\title{
Rotationally Sampled Wind \\ Characteristics and \\ Correlations with MOD-OA \\ Wind Turbine Response
}

\author{
R. L. George
}

J. R. Connell

September 1984

Prepared for the U.S. Department of Energy under Contract DE-AC06-76RLO 1830

Pacific Northwest Laboratory Operated for the U.S. Department of Energy by Battelle Memorial Institute 


\title{
DISCLAIMER
}

This report was prepared as an account of work sponsored by an agency of the United States Government. Neither the United States Government nor any agency thereof, nor any of their employees, makes any warranty, express or implied, or assumes any legal liability or responsibility for the accuracy, completeness, or usefulness of any information, apparatus, product, or process disclosed, or represents that its use would not infringe privately owned rights. Reference herein to any specific commercial product, process, or service by trade name, trademark, manufacturer, or otherwise, does not necessarily constitute or imply its endorsement, recommendation, or favoring by the United States Government or any agency thereof. The views and opinions of authors expressed herein do not necessarily state or reflect those of the United States Government or any agency thereof.

\author{
PACIFIC NORTHWEST LABORATORY \\ operated by \\ BATTELLE \\ for the \\ UNITED STATES DEPARTMENT OF ENERGY \\ under Contract DE-AC06-76RLO 1830
}

\begin{tabular}{|c|c|}
\hline \multicolumn{2}{|c|}{ Printed in the United States of America } \\
\hline \multirow{2}{*}{\multicolumn{2}{|c|}{$\begin{array}{l}\text { Available from } \\
\text { National Technical Information Service }\end{array}$}} \\
\hline & \\
\hline \multirow{3}{*}{\multicolumn{2}{|c|}{$\begin{array}{c}\text { United States Department of Commerce } \\
5285 \text { Port Royal Road } \\
\text { Springfield, Virginia } 22161\end{array}$}} \\
\hline & \\
\hline & \\
\hline \multirow{2}{*}{\multicolumn{2}{|c|}{$\begin{array}{l}\text { NTIS Price Codes } \\
\text { Microfiche A01 }\end{array}$}} \\
\hline & \\
\hline \multicolumn{2}{|c|}{ Printed Copy } \\
\hline & Price \\
\hline Pages & Codes \\
\hline $001-025$ & $\mathrm{~A} 02$ \\
\hline $026-050$ & $\mathrm{~A} 03$ \\
\hline $051-075$ & A04 \\
\hline 076-100 & A05 \\
\hline $101-125$ & A06 \\
\hline $126-150$ & A07 \\
\hline $151-175$ & $\mathrm{~A} 08$ \\
\hline $176-200$ & $\mathrm{~A} 09$ \\
\hline $201-225$ & A010 \\
\hline $226-250$ & A011 \\
\hline $251-275$ & A012 \\
\hline $276-300$ & A013 \\
\hline
\end{tabular}


ROTATIONALLY SAMPLED WIND

CHARACTERISTICS AND CORRELATIONS

WITH MOD-OA WIND TURBINE RESPONSE

R. L. George

J. R. Connell

September 1984

Prepared for

the U.S. Department of Energy

under Contract DE-AC06-76RLO 1830

Pacific Northwest Laboratory

Richland, Washington 99352 



\section{ACKNOWLEDGMENTS}

The authors would like to acknowledge Dr. David Powell for providing statistical expertise and a timely review of the manuscript. Thanks go to NASA-Lewis Research Center for cooperation with wind turbine data and operations, and especially to Dr. David Spera for his informative review. The New Mexico Engineering Research Institute provided much technical and logistical support for the Clayton field program. Betsy Owczarski provided editorial assistance, and Debbie Atkin typed the text and tables, as well as helping with figure preparation. A special thank you goes to Mr. Anthony Cardenas of Clayton, whose resourcefulness and reliability made the task of managing the field program from a distance feasible.

This report was prepared under U.S. Department of Energy Contract DE-AC06-76RLO 1830. The Pacific Northwest Laboratory is operated for the U.S. Department of Energy by Battelle Memorial Institute. 


\section{SUMMARY}

This report presents results of a comprehensive wind and wind turbine measurement program: the Clayton, New Mexico, vertical plane array/MOD-OA project. In this experiment, the turbulent wind was measured for a large array of fixed anemometers located two blade diameters upwind of a 200-kW horizontalaxis wind turbine (HAWT). Simultaneously, key wind turbine response parameters were also measured.

The first of two major objectives of this experiment was to determine the turbulent wind, rotationally sampled to emulate the motion of the wind turbine blade, for the range of different wind speeds and stability classes actually experienced by the wind turbine. The second major objective was to correlate this rotationally sampled wind with the wind turbine blade stress and power, in order to assess the usefulness of the wind measurements for wind turbine loads testing and prediction.

Several hundred hours of usable data were taken during the 16-month field measurement program in 1981 and 1982. From these, 12 data cases, each 8.5 minutes long, were selected, representing four different wind speed and stability regimes: neutral-to-unstable, moderate winds $\left(5-9 \mathrm{~ms}^{-1}\right)$; neutral-to-unstable, high winds (over $9.5 \mathrm{~ms}^{-1}$ ); stable, moderate winds; and stable, high winds. Computer programs were used to produce a time series of the axial wind, or wind normal to the plane of the rotor disk, for each of the 12 cases.

Time series of rotationally sampled winds and wind turbine blade bending moments and power were converted to frequency spectra using Fourier transform techniques. These spectra were used as the basis for both qualitative and quantitative comparisons among the various cases. A quantitative comparison between the rotationally sampled wind input and blade bending response was made, using the Fourier spectra to estimate the blade transfer function. These transfer functions were then used to calculate an approximate damping coefficient for the MOD-OA fiberglass blade. 
Major conclusions of this study are as follows:

- The spectra of rotationally sampled wind show greatly enhanced energy at the blade rotation frequency and higher harmonics for all wind cases. The total energy at higher frequencies is higher for the higher wind speed cases. The energy at each harmonic frequency decreases as the frequency increases.

- The amount of fluctuation energy in the rotationally sampled wind spectra due to mean vertical wind shear can be separated from the energy due solely to turbulence. The energy due to turbulence is 65 to $80 \%$ of the total energy in neutral-to-unstable cases and 10 to $30 \%$ of the total energy in stable cases. All energy at frequencies above twice the blade rotation frequency is due to turbulence. The energy due to turbulence is a linearly increasing function of wind speed for neutral-to-unstable winds.

- A high correlation is observed between the spectra of rotationally sampled wind speed and the blade flapwise bending moment spectra for a 11 cases. A much lower correlation is observed between the wind spectra and the high frequency spectra for MOD-OA generator power.

- The spectra of blade flapwise bending moment show enhanced response at the blade bending harmonic frequencies, previously computed from static measurements. The blade transfer functions are consistent with the blade response expected, knowing these blade harmonic frequencies. Thus, the rotationally sampled wind is shown to be an accurate representation of what the blade actually sees.

- The effective aerodynamic damping coefficient is estimated to be 0.35 for the first harmonic frequency of the MOD-OA fiberglass blade. This result is consistent for the three most representative wind cases. This is far more damping than was measured using static techniques. 


\section{CONTENTS}

ACKNOWLEDGMENTS

SUMMARY

1.0 INTRODUCTION .

2.0 VERTICAL PLANE ARRAY: DESCRIPTION AND DATA ANALYSIS . . . 2-1

2.1 VERTICAL PLANE ARRAY: PHYSICAL DESCRIPTION . . . . 2-1

2.2 WIND SENSORS AND DATA COLLECTION . . . . . . . 2-5

2.3 VPA DATA ANALYSIS . . . . . . . . . .

3.0 ANALYSIS OF VPA WIND CASES . . . . . . . . . . . 3-1

3.1 FEATURES OF THE 12 SELECTED DATA CASES • • • • •

3.2 SPECTRAL ANALYSIS • . . . . . . • • .

3.3 SPECTRAL COMPARISONS OF ALL CASES . • . . . . . . 3-8

3.4 VARIANCE OF WIND SPEED DUE TO ROTATIONAL HARMONICS . . 3-21

4.0 COMPARISON OF MOD-OA BLADE BENDING MOMENT WITH VPA WINDS • • 4-1

4.1 TRANSFER FUNCTION CALCULATIONS . . . . . . . . 4 4-1

4.2 COMPARISON OF TRANSFER FUNCTIONS FOR VARIOUS CASES . . 4-5

4.3 EVALUATION OF TRANSFER FUNCTION TECHNIQUE • • • • • 4-11

5.0 ESTIMATION OF HARMONIC VARIANCES FROM SINGLE TOWER DATA • $\quad$ - $5-1$

6.0 CONCLUSIONS AND RECOMMENDATIONS $\quad . \quad$.

6.1 CONCLUSIONS RELATING TO SPECTRAL ANALYSIS OF

6.2 CONCLUSIONS RELATING TO THE CORRELATION BETWEEN

ROTATIONALLY SAMPLED WINDS AND MOD-OA WIND TURBINE

RESPONSE . . . . . . . . . 6-3

7.0 REFERENCES . . . . . . . . . . . . . . . . 
FIGURES

1 Clayton Vertical Plane Array and MOD-OA Wind Turbine . . . 2-2

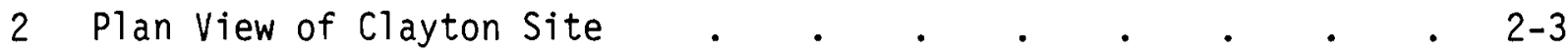

3 Cutaway Drawing of MOD-OA Nacelle . . . . . . . . . $\quad$. 2-4

4 a) Sample Time Series of One-Blade Rotationally Sampled Wind; b) MOD-OA Blade Bending Moment, Lagged in Time to Allow for Advection Time Between Array and Wind Turbine

5 a) Sample Time Series of Two-Blade Rotationally Sampled Winds; b) Time Series of MOD-OA Power . . . . . . 2-10

6 Complete Set of Spectral Plots for Case Cla . . . . . . 3-6

7 Complete Set of Spectral Plots for Case Clb . . . . . . . 3-9

8 Complete Set of Spectral Plots for Case Clc . . . . . 3-10

9 Complete Set of Spectral Plots for Case C2a . . . . . . 3-11

10 Complete Set of Spectral Plots for Case C2b . . . . . 3-12

11 Complete Set of Spectral Plots for Case C2c . . . . . . 3-13

12 Complete Set of Spectral Plots for Case C3a . . . . . . 3-14

13 Complete Set of Spectral Plots for Case C3b . . . . . 3-15

14 Complete Set of Spectral Plots for Case C3c . . . . . 3-16

15 Complete Set of Spectral Plots for Case C4a . . . . . . 3-17

16 Complete Set of Spectral Plots for Case C4b . . . . . 3-18

17 Complete Set of Spectral Plots for Case C4c . . . . . . 3-19

18 Sum of Variance in Five Harmonic Spikes, for All Cases . . . 3-23

19 Variance in Each Harmonic Spike, for All Cases . . . . 3-27

20 a) Spectrum of One-Blade Rotationally Sampled Wind, Case Cla; b) Corresponding Transfer Functions $H(n)$ and $\mathrm{Hb}(n)$; c) Same as Part a, With Wind Data Filtered With a Five Point Lowpass Filter Before Rotational Sampling; d) Transfer Functions Corresponding to Part c; e) Same as Part c, Nine Point Lowpass Filter; e) Transfer Function Corresponding to Part e. 


\section{FIGURES (Continued)}

21 a) Spectrum of One-Blade Rotationally Sampled Wind, C1b;

b) Transfer Functions for Part a; c) Same as Part a, Case Clc; d) Transfer Functions for Part c; e) Same as

Part a, Five Point Lowpass, Case C3a; f) Transfer Functions

for Part e . . . . . . . . . . . . 4-8

22 a) Spectrum of One-Blade Rotationally Sampled Winds, Five Point Lowpass, Case C2b; b) Transfer Functions for Part a;

c) Same as Part a, Case C2b; d) Transfer Functions for Part c;

e) Same as Part a, No Lowpass Filter, Case C4c; f) Transfer

Functions for Part $f$ 


\section{TABLES}

1 MOD-OA Wind Turbine Parameters Recorded by the PNL Data System at Clayton, New Mexico. . . . . . . . 2-5

2 Characteristics of Twelve Data Cases Used in VPA Analyses . . 3-2

3 Wind Speed Variance $\left(\mathrm{m}^{2} / \mathrm{s}^{2}\right)$ Summed for All Five Harmonic Spikes, Excluding Low Frequencies, for All Cases . . . 3-22

4 Wind Speed Variance $\left(\mathrm{m}^{2} / \mathrm{s}^{2}\right)$ in Each Harmonic Spike, Neutral-to-Unstable Cases C1 and C2 . . . . . . . . . 3-25

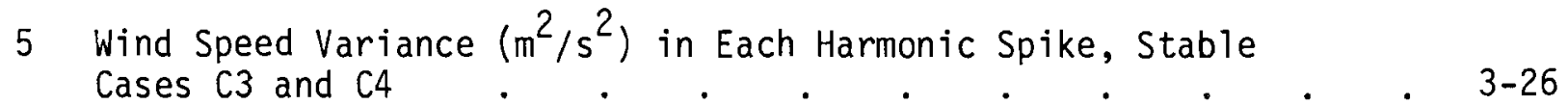

6 Logarithmic Curve Fit Parameters for Harmonic Variances, 12 Cases

7 Summary of Wind Direction and MOD-OA Wind Turbine Characteristics of 12 Data Cases Used in VPA Analyses . . 4-3 


\subsection{INTRODUCTION}

The influence of the turbulent wind on a moving wind turbine blade has recentiy emerged as a significant consideration for wind turbine design. The stresses on the rotating blade caused by instantaneous wind shears encountered by the blade within each revolution have been found to be more severe and more difficult to understand than previously expected. Since 1977, the Pacific Northwest Laboratory (PNL) has been conducting a program of measuring the wind as seen by a rotating horizontal axis wind turbine (HAWT) blade, using fixed arrays of towers and anemometers (Verholek 1978; Connel1 1981), known as vertical plane arrays (VPA).

The technique used to create a time series of wind data for a moving wind turbine blade, from fixed anemometer data, is known as rotational sampling. This term is also used to describe measurement of the wind by sensors that actually rotate, such as split-film anemometers on a rotating boom (Sandborn and Connel1 1984) or on a wind turbine blade (Conne11, George and Sandborn 1984).

The original vertical plane arrays were constructed at Hanford, Washington, a site which was convenient logistically but not very windy. The decision was made in 1980 to build a VPA at a wind turbine site. The purposes of the experiment were 1) to provide a larger data set of VPA wind cases, incorporating additional wind speeds and stability classes and 2) to provide data from both the VPA and a wind turbine (the MOD-OA) in order to correlate the response of the turbine with the incident wind. Primarily because of the flatness of the site and steady wind directions, the MOD-OA site at Clayton, New Mexico, was chosen over other wind turbine sites. The Clayton VPA became operational in May 1981. Simultaneous measurement of wind turbine parameters along with the VPA wind speeds commenced in November 1981.

Preliminary results of the VPA rotationally sampled wind and corresponding MOD-OA response were presented in an earlier paper, along with other rotational sampling concepts (Conne11 and George 1983). That paper established the high correlation between the MOD-OA flapwise bending moment and the rotationaliy sampled wind, using three different data cases. The correlation between MOD-OA power out and a two-blade average rotationally sampled wind was not as pronounced. 
This report describes further analyses of the Clayton VPA data. The purposes of the current study are:

- to characterize the rotationally sampled wind, along with wind turbine parameters, for a wide variety of different wind speeds and stability classes

- to provide a data base of rotationally sampled turbulence statistics for the various cases, as an aid in the development of parameterizations and empirical rotational sampling modeling schemes, as well as to validate theoretical and numerical models of the rotationally sampled wind

- to examine in more detail the correlation between the rotationally sampled wind and wind turbine response; specifically, to compute a transfer function between the rotationally sampled wind and the MOD-OA blade flapwise root bending moment, and to assess this transfer function's usefulness in evaluating both rotor blade characteristics and the suitability of the VPA winds as an input.

The organization of this report is as follows. Chapter 2 starts with a physical description of the VPA, the MOD-OA, and the Clayton site. The next section describes the wind sensors, data collection strategy, and the data collected. Section 2.3 describes the computer programs and techniques used to create the time series of rotationally sampled wind, and shows the correlation of this wind with MOD-OA parameters in the time domain.

Chapter 3 shows the criteria for selection and analysis of 12 different data cases, representing at least 4 different wind regimes. Spectral analysis, or the conversion of fluctuations of the time series data into the frequency domain, is the primary tool used in the data analysis. Spectral density plots are presented for winds and wind turbine parameters for all 12 cases. Statistics of the variance in the wind fluctuations for various high-frequency harmonics of the rotor frequency are used to quantify comparisons among the data cases.

In Chapter 4, transfer functions between the VPA rotationally sampled winds and blade flapwise bending moments are presented. These are compared with the expected blade response function, based on engineering tests of the 
fiberglass rotor blades. Transfer functions from all wind regimes are shown, demonstrating the effects of pitch control of the blade for cases where the MOD-OA power was controlled to the rated power of $200 \mathrm{~kW}$. A calculation is made of the effective damping of the blade flapwise vibrations while the wind turbine is operating.

In Chapter 5, a technique of estimating the energy in the rotationally sampled spectrum, given only mean wind speed and wind shear, is demonstrated. In the last chapter, the results of this study are summarized. 
4 


\subsection{VERTICAL PLANE ARRAY: DESCRIPTION AND DATA ANALYSIS}

A vertical plane array (VPA) of anemometers was operated by PNL between May 1981 and August 1982 at Clayton, New Mexico. The VPA was operated in conjunction with the MOD-OA1, a 200-kW wind turbine operated by the National Aeronautics and Space Administration (NASA) for the U.S. Department of Energy (DOE). In this chapter, we describe the physical configuration of the VPA and the wind sensors used to take the wind data. We also describe the data-taking procedures used at Clayton and the process of selecting data cases. Finally, we discuss the analysis of the wind data using rotational sampling techniques.

\subsection{VERTICAL PLANE ARRAY: PHYSICAL DESCRIPTION}

The VPA consisted of seven triangular guyed stee 1 towers, each 60.6 meters (199 feet) tall (Figure 1). The towers were located in a straight line, which formed a right angle with a line from the VPA center tower to the MOD-OA1 turbine. The towers were placed so that 12 anemometers were evenly spaced around a circle $38.1 \mathrm{~m}(125 \mathrm{ft})$ in diameter. The center of the circle was elevated $30.5 \mathrm{~m}(100 \mathrm{ft})$ above ground level. These dimensions correspond to the height and diameter of the standard MOD-OA rotor. Additional anemometers were located at $60.0 \mathrm{~m}(197 \mathrm{ft})$ on the center tower and at $30.5 \mathrm{~m}(100 \mathrm{ft})$ on the five interior towers.

Data from these additional anemometers are useful for analyzing wind turbine wakes (Connell and George 1982; Doran and Packard 1982) and also for analyzing horizontal wind fluctuations, which are especially useful in verticalaxis wind turbine (VAWT) simulation (George 1984). For the present analysis, we are mainly concerned with correlating wind data from the 12-point ring with data from the MOD-OA1 rotor.

The MOD-OA1 wind turbine was located about $78 \mathrm{~m}(250 \mathrm{ft})$ from the VPA (Figure 2). The direction from the center line of anemometers to the center of the wind turbine was $205^{\circ}$ magnetic, or $216^{\circ}$ geographic. The MOD-OA was a downwind type of wind turbine, so that the rotor blades were on the downwind side of the tower, and passed through the wake of the steel truss tower once per revolution (Figure 3 ). The nominal rotation rate of the rotor was 


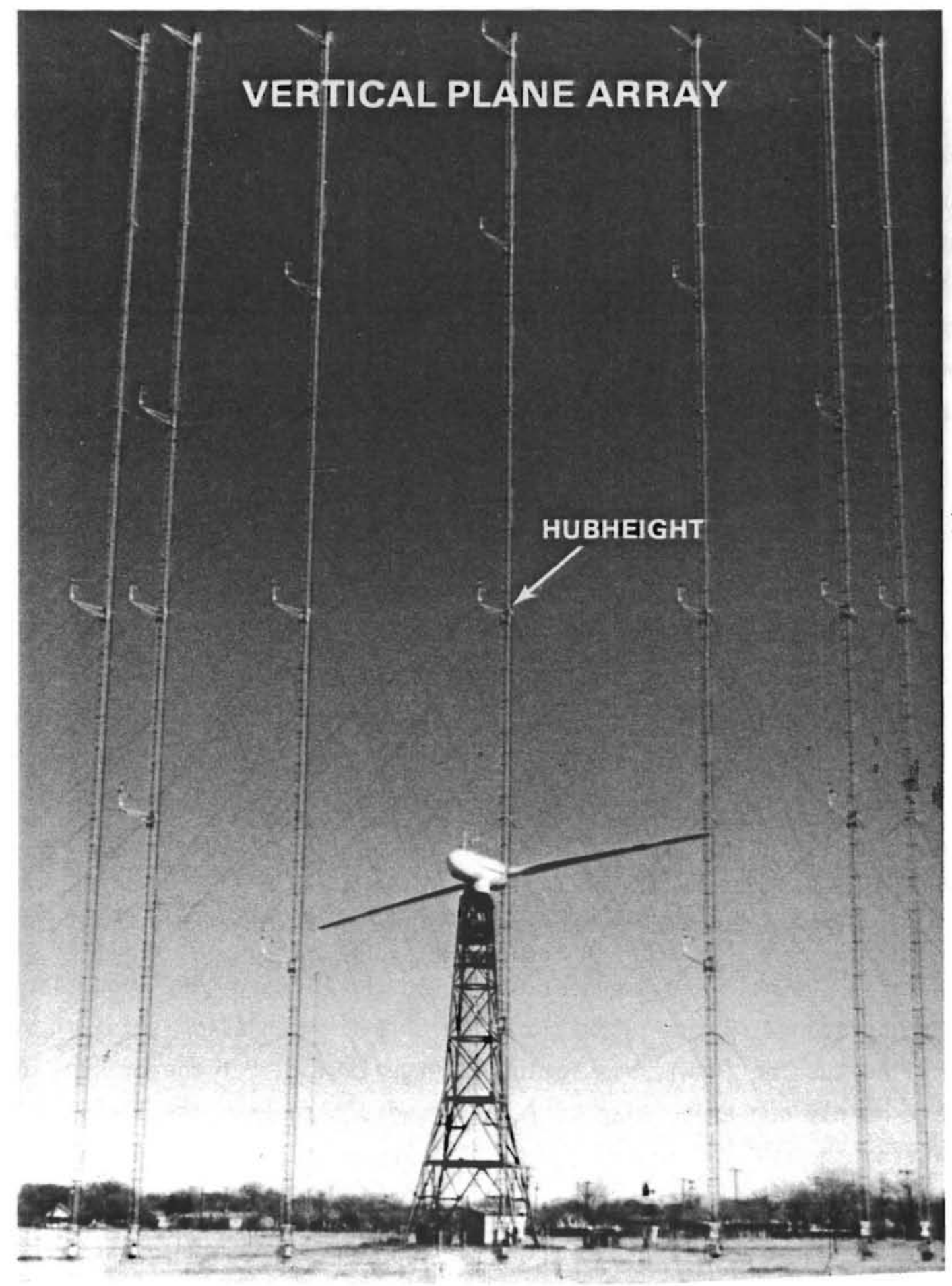

FIGURE 1. Clayton Vertical Plane Array and MOD-OA Wind Turbine. Hub height is $30.5 \mathrm{~m}$; radius of 12 point circle is $19.05 \mathrm{~m}$, same as the radius of the MOD-OA blade. 


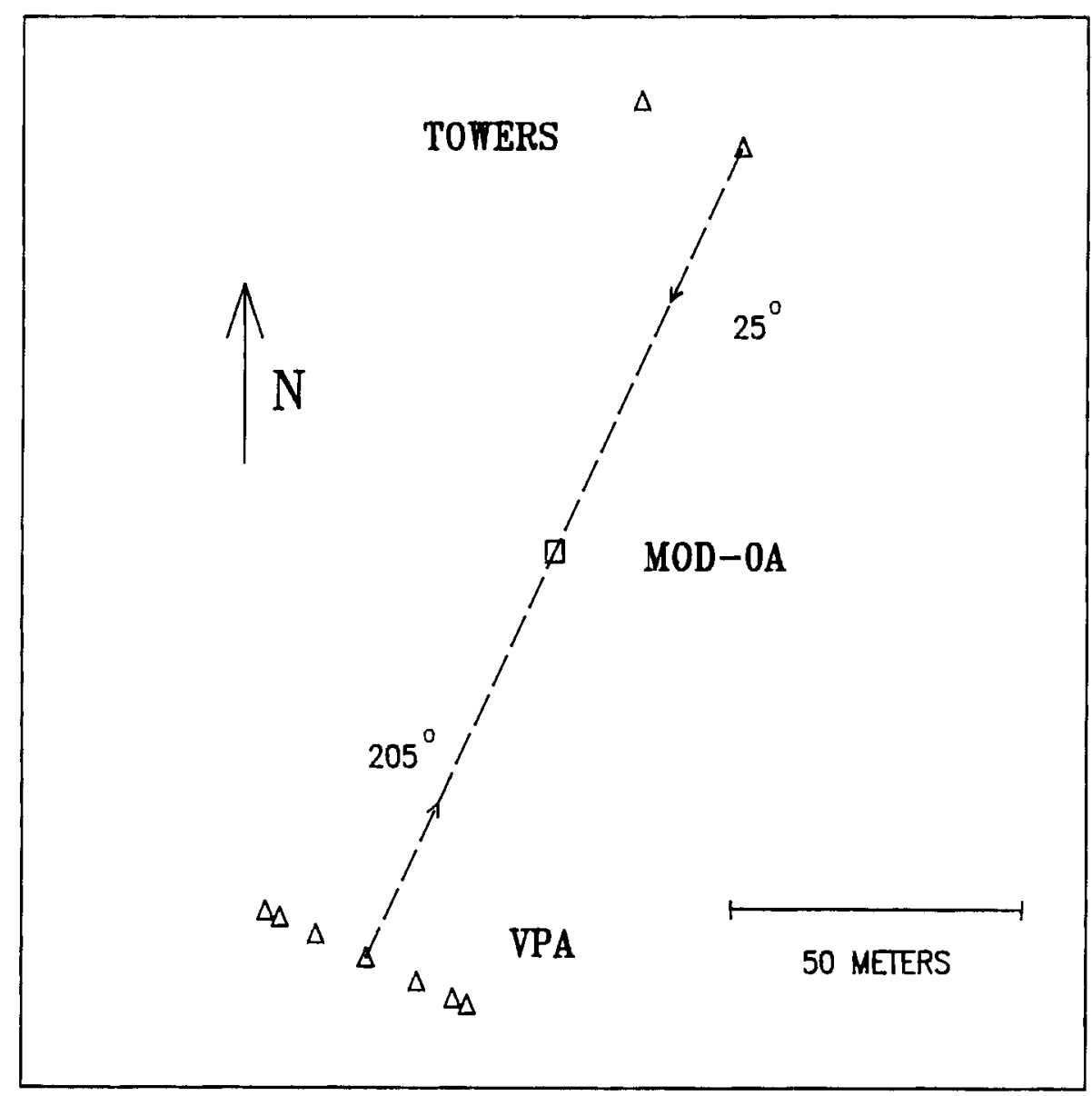

FIGURE 2. Plan View of Clayton Site. Distance from turbine yaw axis to towers in both $205^{\circ}$ and $25^{\circ}$ wind directions is $76.2 \mathrm{~m}$.

40 revolutions per minute $(\mathrm{rpm})$, or $2 / 3$ Hertz $0.66(\mathrm{~Hz})$; thus, each revolution took 1.5 seconds. The actual rotation rate was sometimes slightly slower than $40 \mathrm{rpm}$, due mostly to frequency control problems on the small, diesel-powered clayton city utility.

The wind turbine cut in at a wind speed of $4.2 \mathrm{~m} / \mathrm{s}$ and reached rated power of $200 \mathrm{~kW}$ at $10.0 \mathrm{~m} / \mathrm{s}$. The power was regulated to $200 \mathrm{~kW}$ by hydraulically pitching the entire blade. Below rated power, the pitch was kept at a constant, usually $4^{\circ}$. During the period January 1, 1982, to May 31, 1982, the pitch at below-rated wind speeds was slowly varied in a triangular waveform, as part of a NASA experiment to determine the optimum pitch setting for best performance. The yaw was fully controlled by a ring gear and electric motors. 


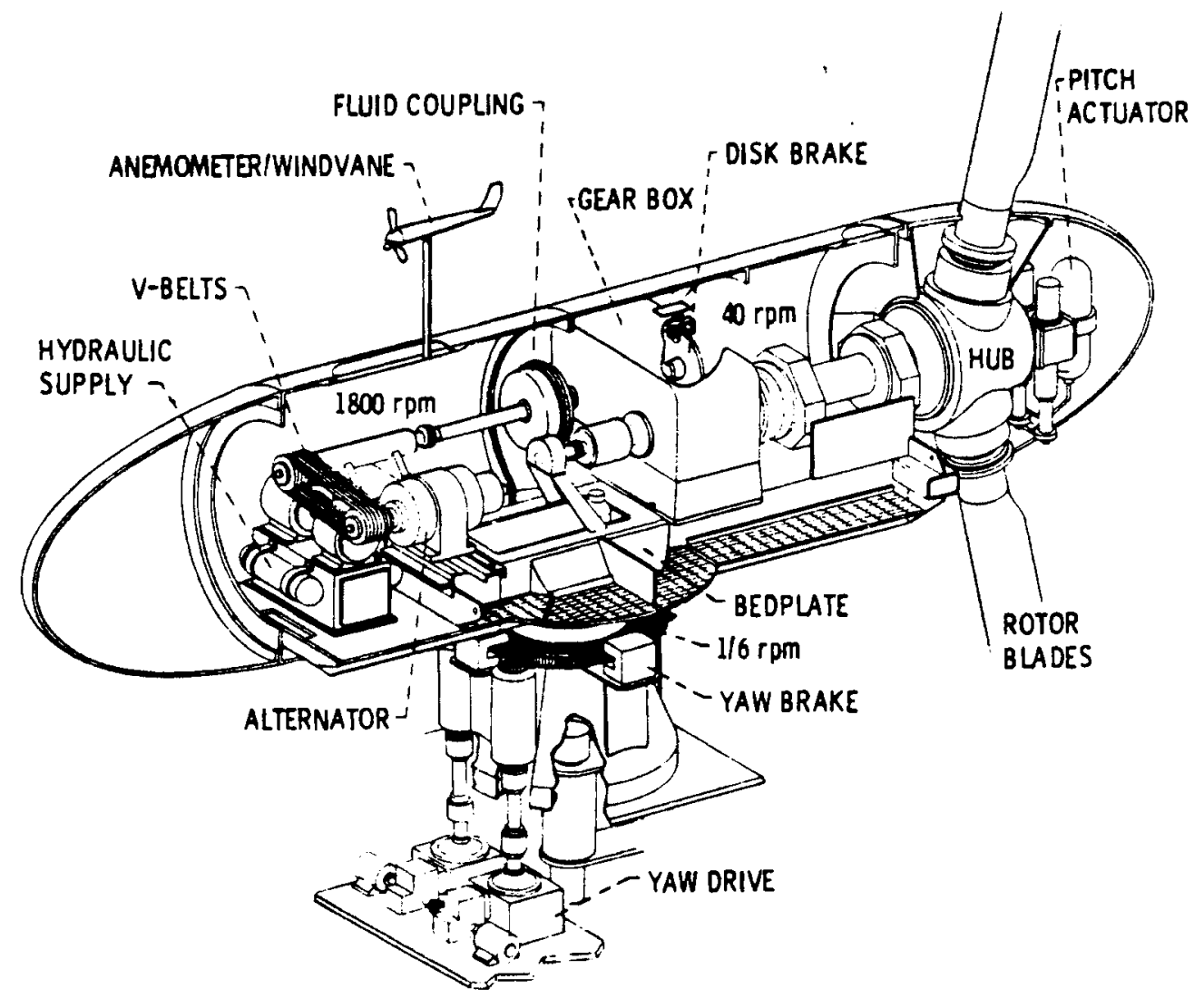

FIGURE 3. Cutaway Drawing of MOD-OA Nacelle (Neustadter 1979)

The microprocessor control system was programmed to keep the yaw direction within $7^{\circ}$ of the long-term mean wind direction.

Analog signals of eight parameters of MOD-OA performance were provided by NASA to the PNL VPA data systems. These are listed in Table 1, along with the source of data of each parameter. "Aerovane" refers to the moveable anemometer/ windvane mounted atop the nacelle, shown in Figure 3.

A11 bending moment data in this study were taken from blade \#19, a transverse filament tape (TFT) fiberglass blade built by Structural Composites Industries (SCI), Pomona, California (Weingart 1982; Sullivan 1983).

Two additional towers, each $30.5 \mathrm{~m}(100 \mathrm{ft}) \mathrm{ta} 11$, were erected $78 \mathrm{~m}(250 \mathrm{ft})$ in the opposite direction from the wind turbine $\left(25^{\circ}\right.$ magnetic, or $36^{\circ}$ geographic) as the VPA. Each tower was instrumented at the $30.5-\mathrm{m}$ level with one anemometer. 
TABLE 1. MOD-OA Wind Turbine Parameters Recorded by the PNL Data System at Clayton, New Mexico

\begin{tabular}{|c|c|c|c|}
\hline Channel & MOD-OA Parameter & Units & Source \\
\hline 1 & Flapwise root bending moment & $f t-1 b$ & strain gauge \\
\hline 2 & Chordwise root bending moment & $f t-1 b$ & strain gauge \\
\hline 3 & Blade pitch & deg & hydraulics \\
\hline 4 & Rotor speed & rpm & rotor \\
\hline 5 & Nacelle direction & deg & yaw drive \\
\hline 6 & Yaw error & $\operatorname{deg}$ & Aerovane \\
\hline 7 & Power out & $\mathrm{kW}$ & alternator \\
\hline 8 & Nacelle wind speed & $\mathrm{m} / \mathrm{s}$ & Aerovane \\
\hline
\end{tabular}

These anemometers were installed on December 16, 1981. Results from wake measurements using these towers have been given by Doran and Packard (1982).

The Clayton MOD-OA site was chosen because of the flatness and uniformity of its terrain. The most frequent wind direction at Clayton is south-southwest or southwest. The VPA was located and the anemometers were exposed so as to give the best wind data in this direction. South to southwest of the VPA is also the location of the flattest, most uniform terrain at this site. Analysis of VPA data has indicated a roughness length (used in logarithmic wind law calculations) of about $0.005 \mathrm{~m}$, a length usually associated with mown grass (Chan et al. 1983). The terrain to the west of the site is much rougher, with a rocky ravine about $100 \mathrm{~m}$ away.

\subsection{WIND SENSORS AND DATA COLLECTION}

The wind sensors used on all the VPA towers are Model 27004 Gill UVW anemometers. (a) Each anemometer consists of three sma 11 propeller anemometers mounted at orthogonal right angles to each other. All anemometers were mounted such that the primary component, known as the $U$ direction, faced into the normal array wind direction of $205^{\circ}$. The cross-wind component is known as $V$ and

(a) Gill anemometers are manufactured by the R. M. Young Co. of Traverse City, Michigan. 
the vertical wind component as $W$. Thus, for a uniform wind direction of $205^{\circ}$, $U$ is the wind speed and $V$ is close to zero. The analysis in this report will utilize both the $U$ and $V$ components.

The propellers mounted on the Gill UVW anemometers were made of rugged black polypropylene and had diameters of $18 \mathrm{~cm}$. The distance constant, a measure of the responsiveness of the propeller to rapid changes in the wind speed, is $3.3 \mathrm{~m}$ for these propellers. For rapid wind speed changes, the propeller acts as a first-order filter with a time constant equal to distance constant divided by mean wind speed (Horst 1973). Wind data from UVW anemometers require correction to account for the fact that the propellers do not respond fully to winds at high angles to the axis of the component. The raw data must be corrected to more accurately represent the wind speed. This correction was performed on all data presented in this report. However, the impact of correction on the measured axial wind speeds is very small. The corrections were performed using the method of Horst (1971), with revised correction coefficients for use with the $18-\mathrm{cm}$ polypropylene propeller.

The data collection program at Clayton was operated on a continuous basis, except for interruptions for equipment upgrade and repair, from May 30, 1981, to July 1, 1982. The system was normally operated by a part-time technician who resided in Clayton. Whenever the wind turbine was observed to be operating with a wind direction within $20^{\circ}$ of either the upwind or downwind direction, the VPA system was placed in the high-speed (4 scans per second), full array, data-taking mode. At this time, the wind turbine high-speed (up to 25 scans per second) data system, if available, was also engaged. If the criteria for wind direction or wind turbine operation were not met, the VPA was placed in the climatological data mode. In this mode, data were taken only from 4 levels on the center tower of the array, and the data rate was 1 scan per second. After November 20, 1981, four channels of MOD-OA data were added to the climatological data system (nacelle direction, yaw error, power out and nacelle wind speed). Each magnetic tape of climatological data contains 3 to 4 days of data.

For the purpose of this report, which is to compare the response of the MOD-OA turbine blades with the rotationally sampled wind, the MOD-OA blade 
bending moments were considered to be vital information. Unfortunately, the bending moment sensors and the amplifiers that provided bending moment signals to the VPA data systems were not always operating correctly throughout the data-taking period. The flapwise bending moment sensors worked continuously from November 20, 1981, to about January 20, 1982, but worked only intermittently after that. The chordwise bending moment sensor did not work correctly until late February 1982 and was subject to the same intermittent failure as the flapwise bending moment sensor (due to problems with the amplifier system

used by both bending moments) after that. This problem was finally resolved on June 8,1982 , after which flapwise bending moments from both blades (18 and 19) and chordwise bending moments from one blade were continuously available.

About 100 hours of data met the criteria of suitability for comparing blade response with input winds. From this data set, 12 cases were selected for intensive analysis in the remainder of this report.

For other purposes, the amount of available.data is much larger. Doran and Packard (1982) have selected data from eight different days for use in the study of wind turbine wakes. Since the MOD-OA power signal was always available, most of the data are usable for wind turbine performance evaluation, in a much more detailed manner than ever before. Miller and Formica (1984) have used the climatological data as input to a model of the MOD-OA control strategy. Chan et a1. (1983) have also used the climatological data to address the problem of wind turbine array modeling. Fu1l array and wind turbine data have also been provided to NASA-Lewis Research Center, designers of the MOD-OA, for use in their blade pitch optimization project.

\subsection{VPA DATA ANALYSIS}

The wind observed by the rotating wind turbine blade can be simulated using the VPA data set. The component of the wind parallel to the wind turbine axis of rotation, or normal to the disk of rotation of the wind turbine, is called the axial wind. A computer program was written that computes the axial component of the wind for any wind direction and nacelle direction.

Axial wind data for any of the 12 anemometers on the array can be interpolated to give the wind speed at any desired time. The time at each point is 
chosen to correspond to the time of passage of a simulated blade. This 'blade' will move from one location on the array to the next location in $1 / 12$ the time it takes for a full revolution. For the MOD-OA, which takes $1.5 \mathrm{~s}$ for a revolution, the time between blade passages at two adjacent anemometers is $1.5 \mathrm{~s} / 12$, or $0.125 \mathrm{~s}$. Thus, by continuing endlessly around the array, one anemometer at a time, we can build up a time series of rotationally sampled winds with a time step of $0.125 \mathrm{~s}$. To simulate the winds on both blades of a two-bladed machine, we take for each point the average of the wind speed at the current location and the wind speed at the opposite location on the array. The same computer program can apply digital lowpass filters to each anemometer location before rotational sampling. In this way we can vary the length scale represented by each wind speed to correspond with the desired response parameter.

The wind turbine parameter that best corresponds to rotational winds is the blade flapwise root bending moment. While the wind turbine is operating at below-rated power, its pitch is constant at an angle of about $4^{\circ}$ with the disk of rotation. Thus, the flapwise bending moment measures the force of the wind in the axial direction.

The chordwise root bending moment of a blade must also be responsive directly to the rotational sampling of the wind, but it will be modified by rotational interaction with the opposite blade and with the whole power train. The generator output power signal reflects the sum of the wind in-plane forcing of both blades. To complicate its comparison with the wind, the power signal also shows effects of damped power train resonance and electrical network frequency and load fluctuations.

Example time series in Figures 4 and 5 can be used to characterize the rotationally sampled winds and wind turbine parameters. Figures 4 and 5 show $18 \mathrm{~s}$ of data, with vertical grid lines every $3 \mathrm{~s}$. Thus, exactly two revolutions of the imaginary blade occur between the vertical grid lines.

In Figure $4 a$, the solid line is the VPA rotationally sampled axial wind speed. The dashed and dot-dash lines are the wind speeds measured from single anemometers, both at the same height $(30.5 \mathrm{~m})$ on opposite sides of the array. For the first eight revolutions on this graph, a persistent horizontal wind 

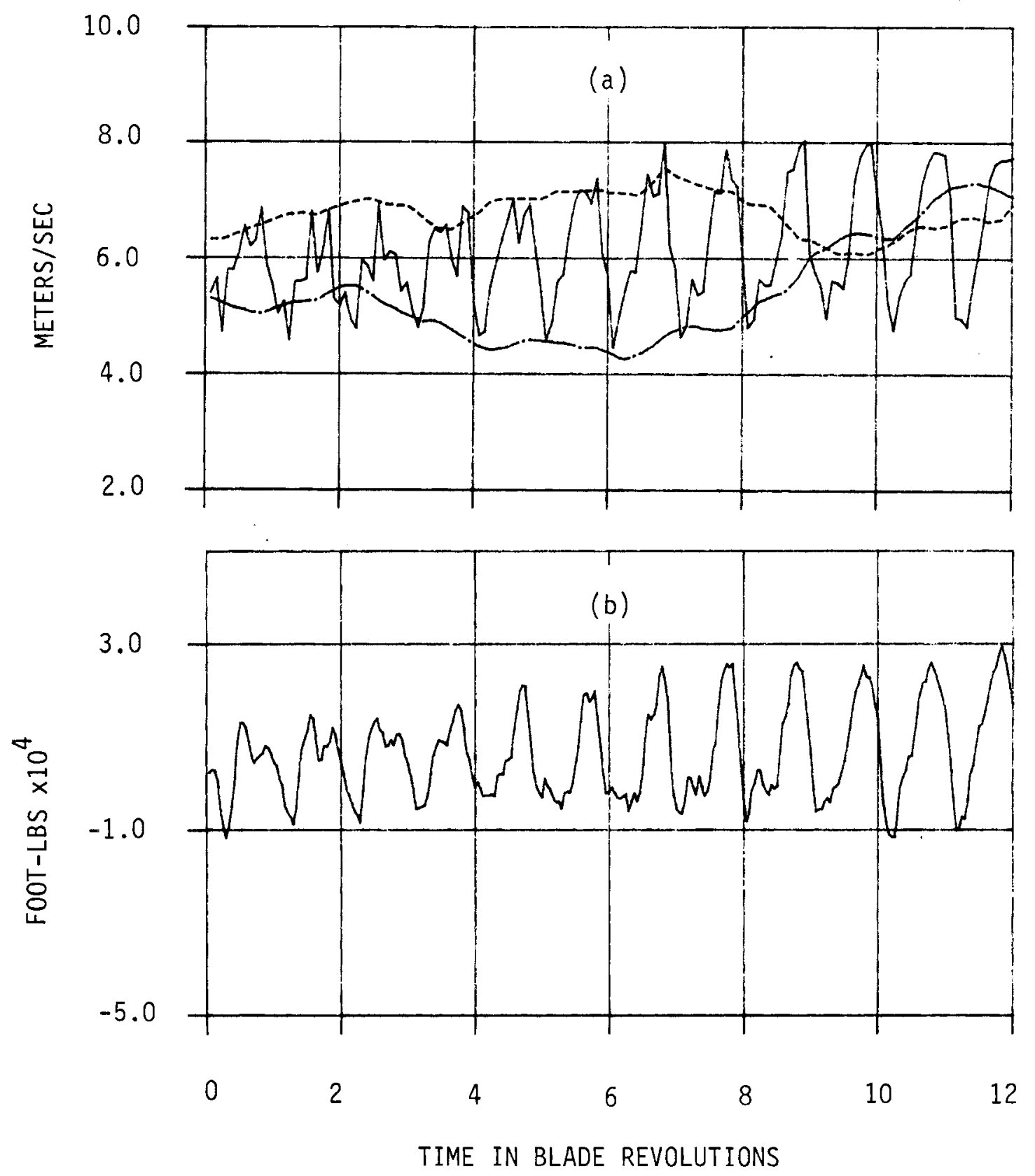

FIGURE 4. a) Sample Time Series of One-Blade Rotationally Sampled Wind (Solid Line). The dashed and chain-dotted lines are the wind speeds measured at hub height on opposite sides of the array.

b) MOD-OA Blade Bending Moment, Lagged in Time to Allow for Advection Time Between Array and Wind Turbine. 

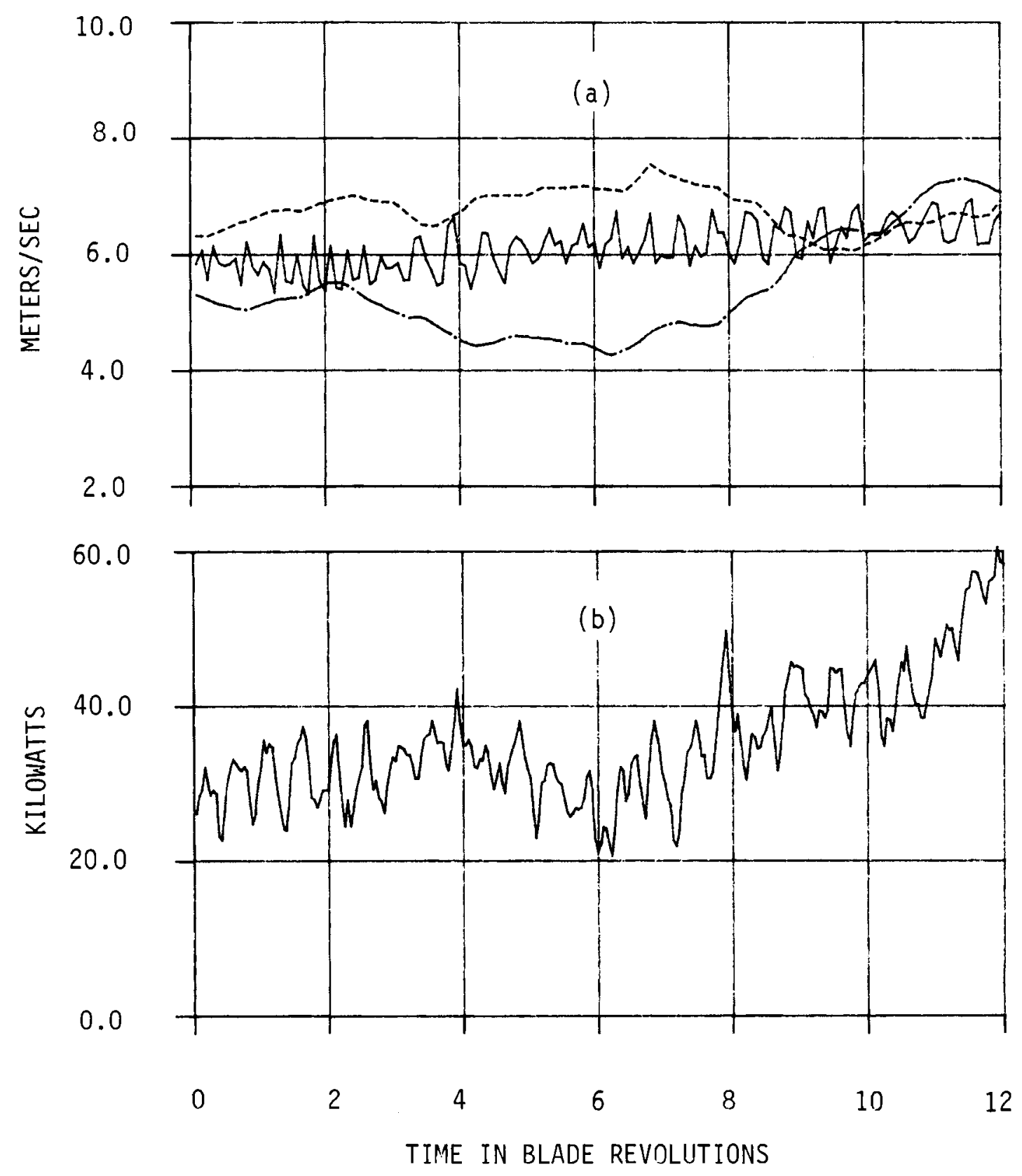

FIGURE 5. a) Sample Time Series of Two-Blade Rotationally Sampled Winds (Solid Line). Same time period as Figure 4a. Hub height winds as in Figure $4 a$.

b) Time Series of MOD-OA Power. Same time period as Figure 4b. 
shear of 2 to $3.5 \mathrm{~m} / \mathrm{s}$ existed across the disk. Toward the end of this time period, the horizontal shear disappeared, and the cyclic wind fluctuations were due mostly to vertical wind shear. This also produced a change in the phase of the cyclic signal. At exactly 2 revolutions, the wind speed was at a minimum, whereas at 12 revolutions, it had shifted to a maximum.

Figure $4 b$ is a time series of flapwise bending moments from the MOD-OA. It has been lagged in time by $14.5 \mathrm{~s}$ compared to the wind trace in Figure $4 \mathrm{a}$. This allows for the advection time of the wind between the array and the rotor. The correlation between the wind and the blade response is high but by no means exact. These data were carefully selected to have a wind direction exactly between the array and the wind turbine. For comparisons using statistical and spectral analysis, perfect alignment of the wind is not necessary, if we assume that the winds and the terrain are horizontally homogeneous over a long period of time.

The correlation between blade bending and the array axial wind is reduced by several influences:

- wind direction.fluctuations, both short- and 1ong-term

- large yaw errors which introduce additional effects on the rotor due to nacelle wakes, etc.

- tower shadow, the wake of the steel truss tower on the blades as they pass behind it.

Figure $5 \mathrm{a}$ shows the two-blade average rotationally sampled wind speed for the same time period as Figure 4. Two-blade averaging removes the once-perrevolution cycle. Fluctuations with two cycles per revolution are predominant. The first three revolutions have four fluctuations per revolution. The MOD-OA power, shown in Figure 5b, has a character similar to the two-blade wind, with two cycles per revolution. However, the correlation with the two-blade wind does not appear to be high. The noncyclic value of the power is very sensitive to small changes in the disk average wind speed.

In this chapter, we have described the Clayton vertical plane array and MOD-OA wind turbine, and the simultaneous measurement of the wind at the array 
and the blade stress and power at the wind turbine. We have shown how the VPA wind data can be processed into a time series of wind rotationally sampled around a ring of anemometers and have suggested that this should have a high correlation with the time series of wind turbine parameters. In the next chapter, we convert these time series into the spectral domain using a Fourier transform, and use the resulting spectral plots to compare wind data for different wind speeds and atmospheric stability, as well as to correlate the rotationally sampled wind with wind turbine response. 


\subsection{ANALYSIS OF VPA WIND CASES}

This chapter describes the selection of 12 data cases, representative of four different wind regimes. Spectral analysis techniques are used to show the fluctuation energy content of the rotationally sampled wind as well as wind turbine blade bending and power.

\subsection{FEATURES OF THE 12 SELECTED DATA CASES}

The minimum criteria for selecting data for the present analysis of MOD-OA blade response were 1) the wind turbine was operating, with the flapwise root bending moment available; and 2) no yaw motion of the wind turbine occurred within the period in question. Data meeting these requirements were then screened according to the following criteria in descending order of importance:

- Low observed yaw error. The yaw error was determined by taking the difference between the array average wind direction and the nacelle direction. The nacelle direction signal was calibrated in the field by pointing the MOD-OA directly at the center of the array and recording the signal out. This was accurate to within $2^{\circ}$. The yaw error criterion eliminated many otherwise good data periods that had yaw errors of $15^{\circ}$ to $40^{\circ}$, due presumably to instrumentation problems with the Aerovane wind direction sensor which was used to control the nacelle direction.

The yaw errors ranged from $0^{\circ}$ to $9^{\circ}$ for the cases selected. The wind turbine had a definite tendency to maintain a larger yaw error at higher wind speeds. This is presumed to be due to wake or induction effects, which influence the direction of the nacelle-mounted Aerovane. Thus, almost all the high-wind-speed cases had average yaw errors greater than $5^{\circ}$.

- Wind direction close to array direction. Directions within $10^{\circ}$ of the array were desired, but due to the sparseness of data meeting the yaw error criterion for the higher wind speed classes, directions up to $21^{\circ}$ off the array were accepted.

- Wind direction stationarity. This was usually good for the stable wind cases, not very good for neutral to unstable cases. 
Wind speed stationarity had the lowest priority in this data selection scheme, since the cyclic response of the rotating wind turbine was assumed to be basically independent of longer term wind speed fluctuations.

Characteristics of the 12 data cases chosen are listed in Table 2. Each data case is $8.5 \mathrm{~min}$ long. The turbulence intensity, o/ws, was computed by taking the standard deviation of the hub-height wind speed after removing all fluctuations longer than about 2 min and dividing this standard deviation by the mean wind speed. The mean wind shear is measured from the top of the rotor disk $(49.5 \mathrm{~m})$ to the bottom $(11.4 \mathrm{~m})$. The total shear and shear rate per meter of elevation gain (last column) were taken from shear profiles that represent a fourth-order polynomial fit to the observed wind speed profile versus height. This was used to eliminate the effects of small errors in wind speed from one anemometer to the next.

TABLE 2. Characteristics of Twelve Data Cases Used in VPA Analyses. Each case is 8.5 minutes 1ong.

\begin{tabular}{|c|c|c|c|c|c|c|}
\hline \multirow{2}{*}{$\begin{array}{c}\text { Case } \\
\# \\
\end{array}$} & \multirow[b]{2}{*}{ Date } & \multirow{2}{*}{$\begin{array}{c}\text { Start } \\
\text { Time, } \\
\text { MST } \\
\end{array}$} & \multirow[b]{2}{*}{$\begin{array}{l}\text { Mean Wind } \\
\text { Speed, m/s }\end{array}$} & \multirow[b]{2}{*}{ o/WS } & \multicolumn{2}{|c|}{ Disk Mean Shear } \\
\hline & & & & & $\begin{array}{c}\text { Total, } \\
\mathrm{m} / \mathrm{s}\end{array}$ & $\begin{array}{c}\text { Per } \\
\text { Meter }\end{array}$ \\
\hline $\begin{array}{l}\text { Cla } \\
\text { Clb } \\
\text { Clc }\end{array}$ & $\begin{array}{l}11 / 25 / 81 \\
06 / 28 / 82 \\
06 / 28 / 82\end{array}$ & $\begin{array}{l}1211 \\
1350 \\
0818\end{array}$ & $\begin{array}{l}7.66 \\
6.82 \\
7.68\end{array}$ & $\begin{array}{l}0.089 \\
0.120 \\
0.089\end{array}$ & $\begin{array}{l}0.584 \\
0.902 \\
0.955\end{array}$ & $\begin{array}{l}0.015 \\
0.024 \\
0.025\end{array}$ \\
\hline $\begin{array}{l}\mathrm{C} 2 \mathrm{a} \\
\mathrm{C} 2 \mathrm{~b} \\
\mathrm{C} 2 \mathrm{c}\end{array}$ & $\begin{array}{l}01 / 01 / 82 \\
12 / 04 / 81 \\
06 / 30 / 82\end{array}$ & $\begin{array}{l}1231 \\
1303 \\
1740\end{array}$ & $\begin{array}{r}9.87 \\
11.19 \\
10.71\end{array}$ & $\begin{array}{l}0.077 \\
0.080 \\
0.080\end{array}$ & $\begin{array}{l}1.812 \\
0.651 \\
1.506\end{array}$ & $\begin{array}{l}0.048 \\
0.017 \\
0.040\end{array}$ \\
\hline $\begin{array}{l}\text { C3a } \\
\text { C } 3 b \\
\text { C3c }\end{array}$ & $\begin{array}{l}07 / 01 / 82 \\
12 / 18 / 81 \\
12 / 14 / 81\end{array}$ & $\begin{array}{l}0124 \\
1608 \\
1624\end{array}$ & $\begin{array}{l}5.95 \\
5.90 \\
5.70\end{array}$ & $\begin{array}{l}0.100 \\
0.052 \\
0.036\end{array}$ & $\begin{array}{l}1.621 \\
2.357 \\
2.294\end{array}$ & $\begin{array}{l}0.043 \\
0.062 \\
0.060\end{array}$ \\
\hline $\begin{array}{l}\text { C4a } \\
\text { C4b } \\
\text { C4c }\end{array}$ & $\begin{array}{l}01 / 01 / 82 \\
01 / 01 / 82 \\
01 / 01 / 82\end{array}$ & $\begin{array}{l}1803 \\
1546 \\
1825\end{array}$ & $\begin{array}{l}12.52 \\
12.32 \\
14.00\end{array}$ & $\begin{array}{l}0.086 \\
0.083 \\
0.072\end{array}$ & $\begin{array}{l}3.566 \\
3.313 \\
4.246\end{array}$ & $\begin{array}{l}0.094 \\
0.087 \\
0.111\end{array}$ \\
\hline
\end{tabular}

The 12 data cases represent four wind regimes: daytime neutral-to-unstable conditions with low and high wind speeds, and nighttime stable conditions with low and high wind speeds. There are three examples of each regime. 
- Case Cl represents daytime, neutral-to-unstable conditions, with low wind speeds. These cases at Clayton were characterized by very low vertical wind shears. The turbulence intensities of 0.09 to 0.12 are typical for a flat site. Mean wind shears are $10 \mathrm{w}$, being in a 11 cases less than $1 \mathrm{~m} / \mathrm{s}$ across the disk of rotation. Low-wind-speed cases in $\mathrm{Cl}$ and $\mathrm{C} 3$ were chosen so that the wind turbine was always operating at below its rated power of $200 \mathrm{~kW}$ (constant blade pitch).

- Case C2 contains data for higher wind speeds and daytime, neutral-tounstable conditions. The turbulence intensity was slightly lower for these cases. Moderate vertical wind shears were present, except for case $\mathrm{C} 2 \mathrm{~b}$, which had a very low wind shear. The high-wind-speed cases, $\mathrm{C} 2$ and $C 4$, were chosen to have MOD-OA power at or close to rated power (variable blade pitch).

- Cases C3 and C4 represent evening and nighttime conditions with more stable wind shear profiles. Case $\mathrm{C} 3 \mathrm{a}$ is only slightly stable, and has higher turbulence intensity levels more characteristic of neutral flows. Cases c $3 b$ and $C 3 c$ have extremely low turbulence levels and high wind shears. Case $c 4$ has high wind speeds, very high vertical wind shears, and levels of turbulence intensity similar to the neutral cases.

\subsection{SPECTRAL ANALYSIS}

Power spectral density (PSD) functions were chosen for data analysis to provide a means of comparison between wind data and wind turbine response in a form familiar to both boundary-layer meteorologists and wind turbine engineers. The PSD functions were created using a Fast Fourier Transform (FFT) routine. Variances integrated over the spectral domain are also computed using the FFT routine. The FFT spectral analysis technique requires that the input data stream consist of a number of data points equal to an integral power of 2 . The data segments analyzed in this paper are 8.53 min $10 n g$, or $512 \mathrm{~s}$. For rotational winds, the data rate is 8 per second (one data point each $0.125 \mathrm{~s}$ ), each spectrum contains 4096 data points $\left(2^{12}\right)$, and the highest frequency is $4.0 \mathrm{~Hz}$. For wind turbine parameters, the data rate is 16 samples per second, the spectra contain 8192 data points, and the highest frequency is $8.0 \mathrm{~Hz}$. 
Spectral density functions are displayed using log-log graphs in this report. Figure 6 shows the spectral density plots of VPA one-blade and twoblade winds, MOD-OA flapwise bending moment and power, the VPA one-blade wind with the mean wind (and therefore all mean shears) removed, and the Eulerian hub-height wind spectrum. These spectra are from case Cla.

A PSD plot from the VPA for a single anemometer at hub height is shown in Figure $6 \mathrm{f}$. Atmospheric turbulence, when plotted in this manner, usually exhibits a falloff with increasing frequency which has a slope of $-5 / 3$ on a $\log -10 \mathrm{~g}$ plot, as is indicated with a diagonal dashed line on Figures $6 a, b$ and $f$. The deviation of our observed response from the theoretical is due to the lack of frequency response of the propeller anemometer. For this case, the half power frequency for propeller rolloff was $0.37 \mathrm{~Hz}$. We will refer to the rotation rate of the wind turbine as $n_{0}$. For the MOD-OA, $n_{0}=0.667 \mathrm{~Hz}$, or $40 \mathrm{rpm}$. Integer multiples of $n_{0}$ are also referred to as the number of cycles of fluctuation per revolution of the blade, abbreviated ' $P$ '. Thus, $1 P=n_{0}, 2 P=2 n_{0}$, etc.

On all plots, the $1 \mathrm{P}$ and $2 \mathrm{P}$ frequencies are marked with vertical dashed lines. The irregular dashed curve on all plots except Figure $6 \mathrm{e}$ is the full disk spectrum, obtained using the time series of average wind using all 12 anemometers on the array, not rotationally sampled.

For one-blade rotationally sampled axial winds (Figures $6 a$ and e), a spike occurs in the power spectrum at all integer multiples of $n_{0}$. For two-blade spectra (Figure 6b), only even multiples (2P, 4P, etc.) are present. The size of the spikes decreases with increasing frequency in a very regular manner. The size of the $2 \mathrm{P}$ and $4 \mathrm{P}$ spikes on the two-blade spectrum (Figure $6 \mathrm{~b}$ ) is identical to the corresponding spikes on the one-blade spectrum (Figure 6a). The diagonal dashed line on these two figures is the maximum spectral density we would expect, given the Eulerian spectrum in Figure $6 \mathrm{f}$. Thus, both the one-blade and the two-blade spectra have more energy at high frequencies than any fixed anemometer could measure. Furthermore, the spectrum of one-blade wind speed with the means removed (Figure 6e) demonstrates that almost all this energy is due to turbulence in the wind and not to mean vertical wind shear. 
The characteristic VPA rotationally sampled spectrum in Figures $6 a$ and $e$ has three major features, which can be explained by physical arguments. The dip in the mid-frequencies, from about 0.05 to $0.5 \mathrm{Hertz}$, is caused by full disk averaging of the wind. The spikes are caused by wind eddies large enough to persist, on some sector of the disk of rotation, for several revolutions of the blade. These can occur at any place on the disk of rotation during the course of our 8.5 minute data periods. The floor, or level of the dips between spikes, is caused by random fluctuations in the rotationally sampled wind that are not repeated from one revolution to the next. This level is often very close to the level of the Eulerian hub-height spectrum (Figure $6 f$ ) at the frequency $\mathrm{n}_{0}$. In this case, both the floor and the Eulerian spectrum at $n_{0}$ were about $10^{-2}$.

The MOD-OA parameters, Figures $6 c$ and $6 d$, have been normalized so that the low-frequency average is 1.0 . This allows them to be compared with the full disk wind spectrum, which is also normalized and plotted as a dashed line on each plot. Both the flapwise bending moment and the power out show a remarkable correlation with the full disk wind spectrum in the low frequencies.

The first two natural harmonic blade bending frequencies, as measured by static testing at NASA-Lewis Research Center (Sullivan 1983), are $1.5 \mathrm{~Hz}$ and $4.3 \mathrm{~Hz}$, respectively. These frequencies are marked with vertical dashed 1 ines in Figures $6 \mathrm{c}$ and $\mathrm{d}$. Maxima in the floor levels of the flapwise bending moment (Figure 6c) are plainly visible at these two frequencies. The resemblance between Figures $6 a$ and $6 c$ is quite striking. The amplitude from peak-to-floor of the spikes is somewhat larger for the blade bending than for the VPA wind speed.

The MOD-OA power out spectrum, Figure $6 \mathrm{~d}$, bears a less than striking resemblance to the VPA two-blade spectrum in Figure $6 \mathrm{~b}$. In addition to the expected spikes at the even harmonics, small spikes exist at the odd harmonics. This may be due to a lack of complete symmetry between the two blades, as well as coupling between stresses in the flapwise and chordwise directions, previously observed for the MOD-OA and other wind turbines (Spera 1977). Some response at the flapwise harmonic frequencies, $1.5 \mathrm{~Hz}$ and $4.3 \mathrm{~Hz}$, is also apparent. 

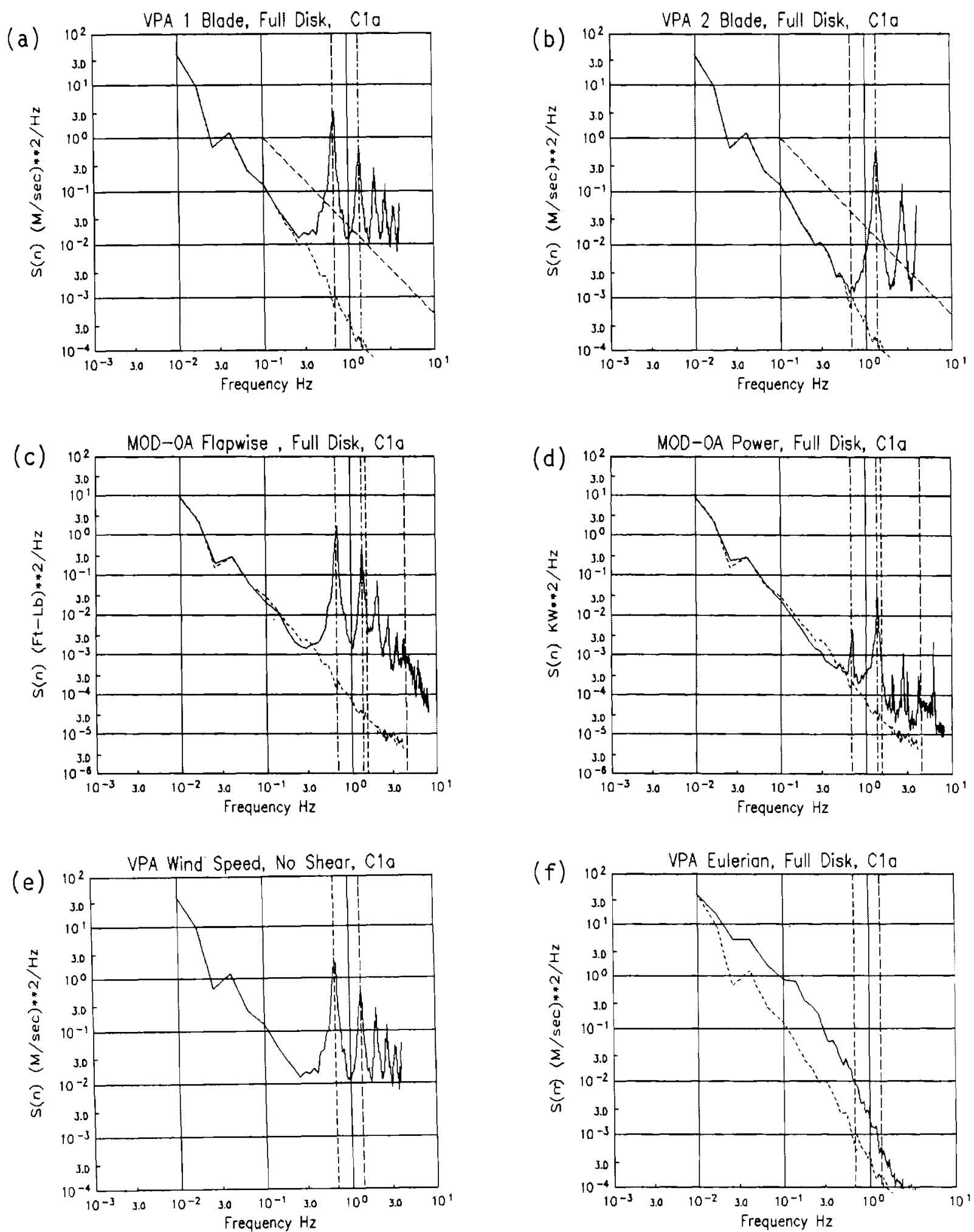
FIGURE 6. Complete Set of Spectral Plots for Case Cla. a) Rotationally sampled, one-blade; b) rotationally sampled, two-bladed;

c) MOD-OA flapwise bending moment; d) MOD-OA power; e) one-blade rotationally sampled with mean shears removed; f) hub height Eulerian wind, and full disk average (dashed line). The full disk average spectrum is also shown in a, b, c and d. Vertical dashed lines mark the $1 \mathrm{P}$ and $2 \mathrm{P}(0.667 \mathrm{~Hz}$ and $1.333 \mathrm{~Hz})$ on all plots. Vertical dashed lines also mark the blade resonance frequencies, $1.5 \mathrm{~Hz}$ and $4.3 \mathrm{~Hz}$, in $\mathrm{c}$ and $\mathrm{d}$. The diagonal dashed lines in $a$ and $b$ mark the upper limits of Eulerian turbulence for this case. 
Overal1, the power is attenuated more than the flapwise bending moment is at higher frequencies, due in part to the presence of a fluid coupling between the rotor and the alternator.

\subsection{SPECTRAL COMPARISONS OF ALL CASES}

The data presented in Figure 6 are from a daytime, neutral-to-unstable wind regime with the wind turbine operating at below its rated power. The next 11 figures show the same characteristics for 11 other cases, with different wind characteristics. Figures 7 through 17 show the same wind and wind turbine data as Figure 6 , with the following differences:

- diagonal $-5 / 3$ slope lines are not included

- full disk spectra are included only on the last plot, $f$ in each figure

- MOD-OA bending moment and power are not normalized, but are shown in engineering units. Time series of flapwise bending moment were reduced by a factor of $10^{4}$ in the time series, or $10^{8}$ in the spectra, in order to be compatible with available software. Thus, the flapwise spectral plots actually range from $10^{6}$ to $10^{12}$ in the $y$-axis.

For the most part, the three cases within each wind regime look about the same. All three cases are shown in order to verify any generalizations we might make about each wind regime.

Cases C1b and C1C (Figures 7 and 8) look basically the same as case Cla (Figure 6). The floor level is about $10^{-2} \mathrm{~m}^{2} \mathrm{~s}^{-2} \mathrm{~Hz}^{-1}$. The no-shear plots (Figures $7 e$ and $8 e$ ) differ from the standard VPA plots only at the tip of the $1 P$ spike. The greatest differences are in the MOD-OA power, where cases $C 1 b$ and $\mathrm{C} 1 \mathrm{C}$ have smaller spikes at $1 \mathrm{P}$ and $3 \mathrm{P}$, and a more definite response at about $4.3 \mathrm{~Hz}$, the second flapwise harmonic of the blade.

Cases $C 2 a, b$ and $c$ (Figures 9, 10 and 11), the higher wind speed neutralto-unstable wind cases, are significantly different from the $C 1$ cases. The floor level of the VPA wind spectrum is increased to about 3 to $5 \times 10^{-2}$. This makes the spikes in the higher harmonics look small, but they are actually higher than those from $\mathrm{Cl}$. This represents substantially stronger wind gusts 

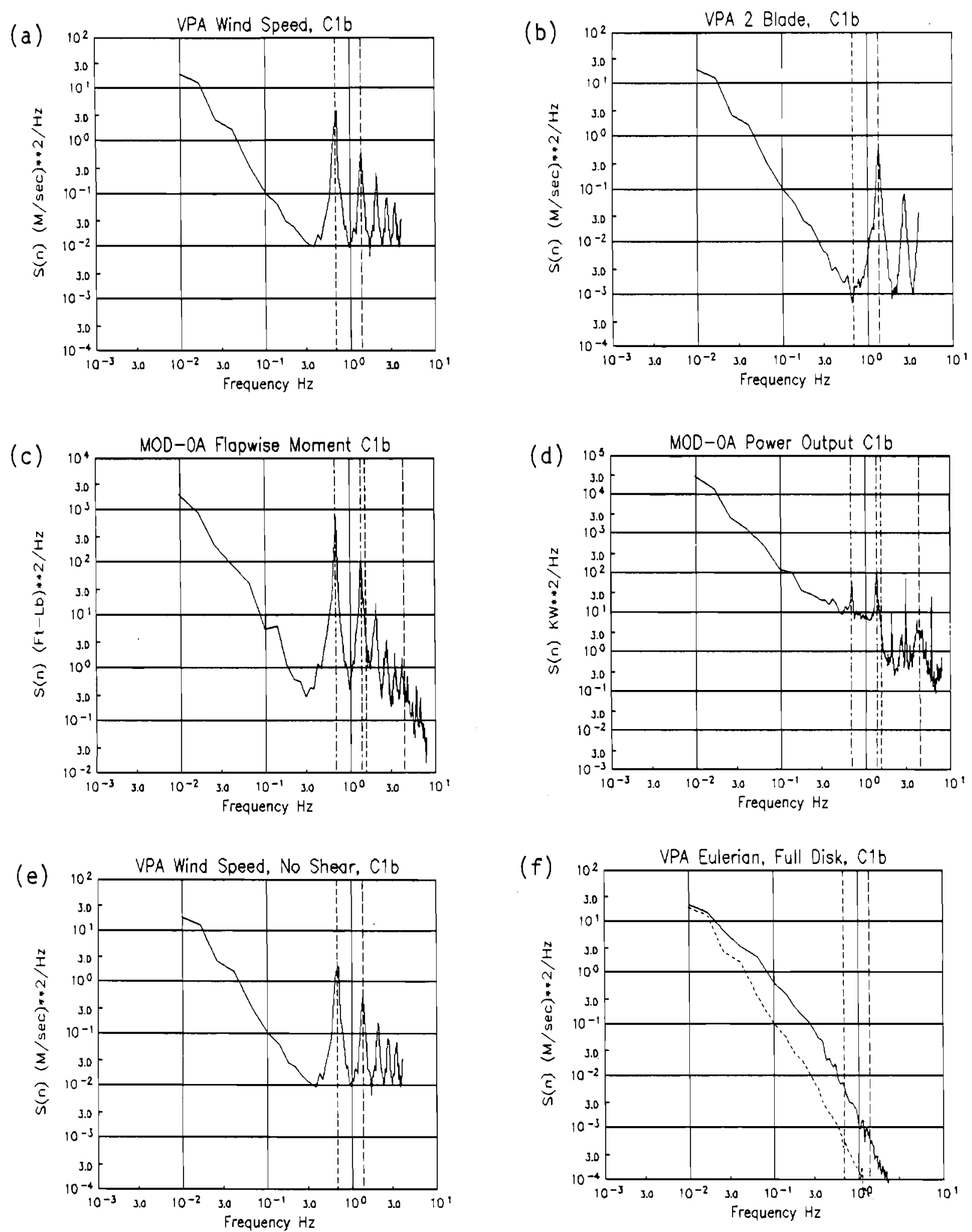

FIGURE 7. Complete Set of Spectral Plots for Case C1b. Same as Figure 6, with diagonal lines omitted from $a$ and $b$ and full disk spectrum omitted from $a, b, c$ and $d$. 

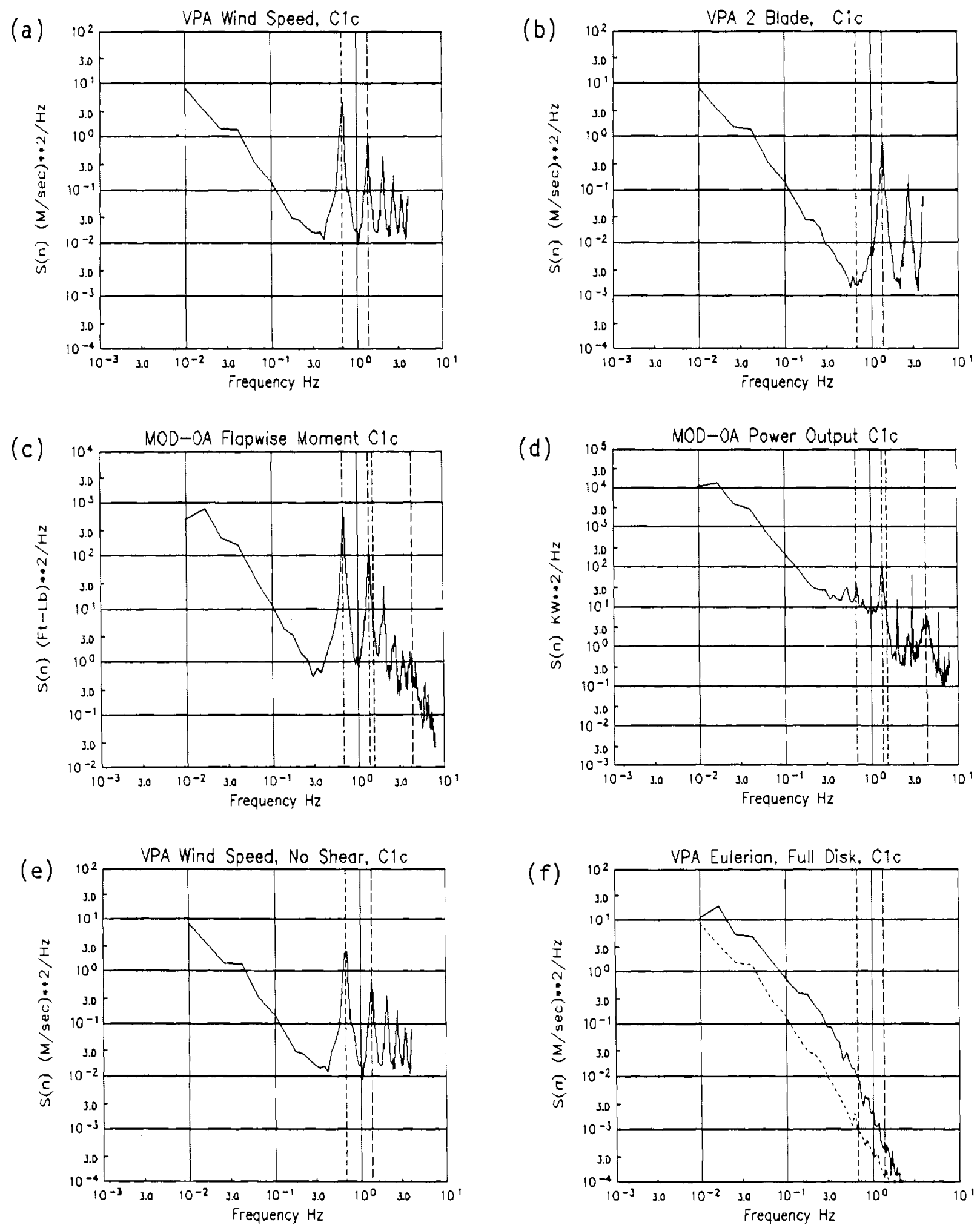

FIGURE 8. Complete Set of Spectral Plots for Case ClC 

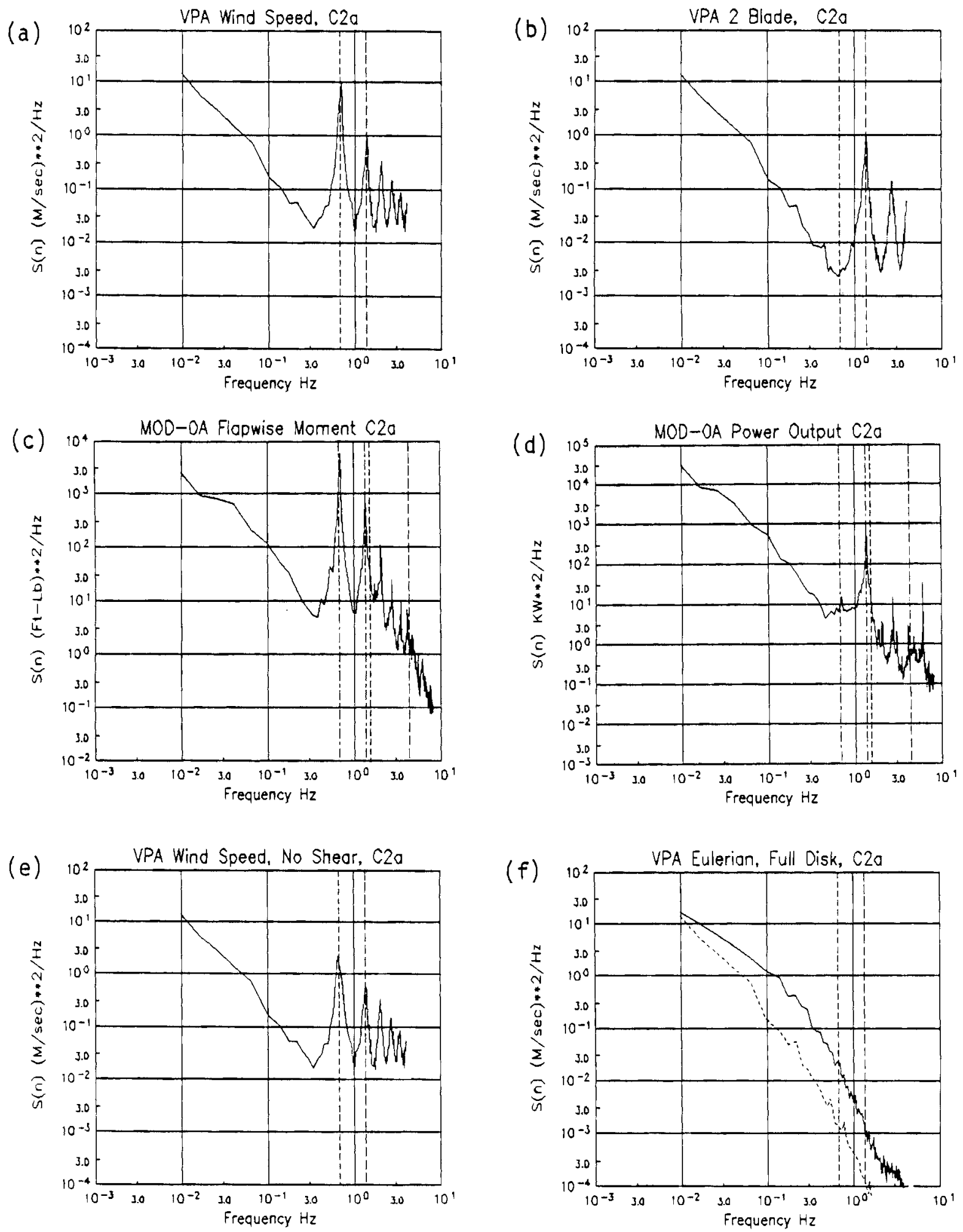

FIGURE 9. Complete Set of Spectral Plots for Case C2a 

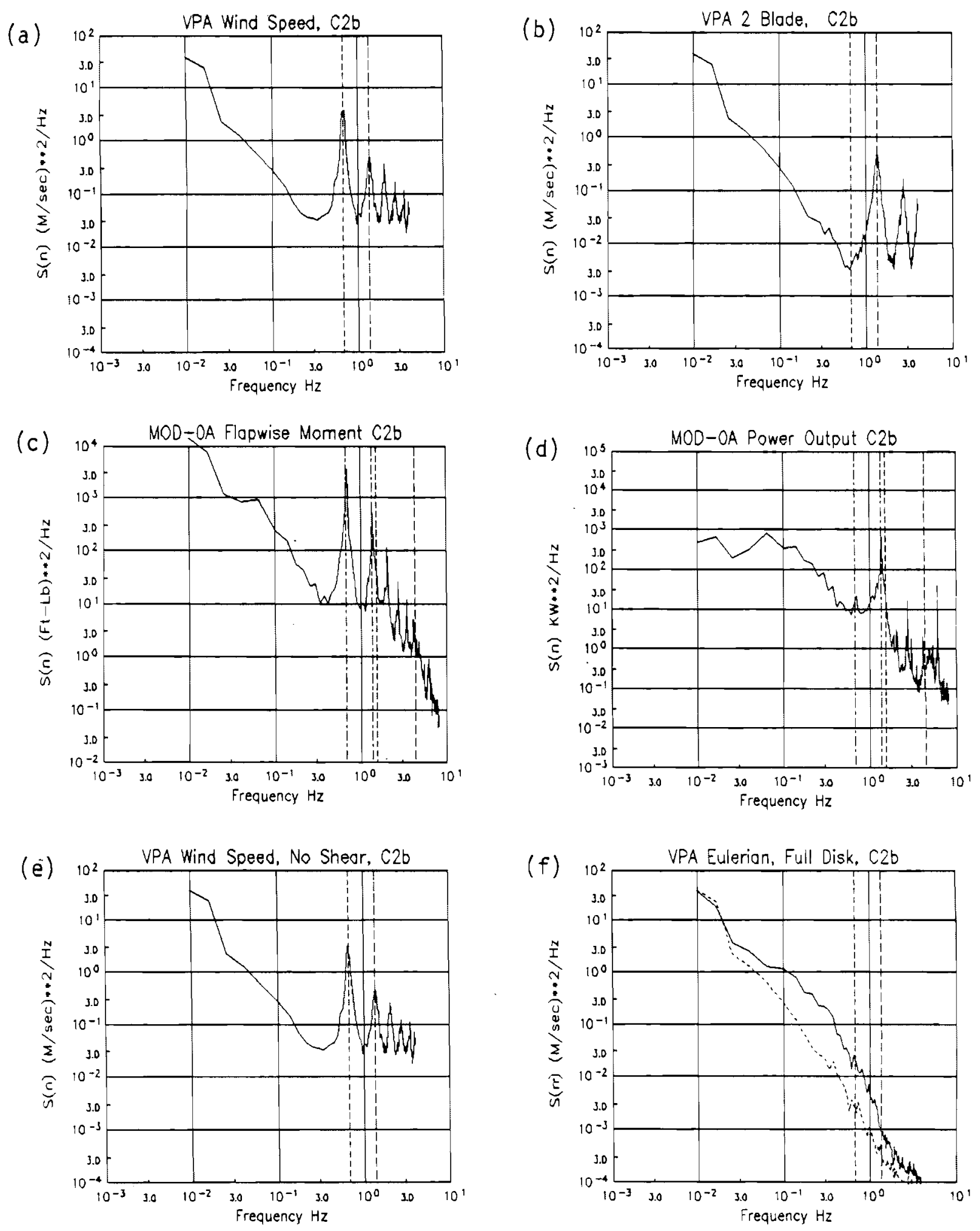

FIGURE 10. Complete Set of Spectral Plots for Case C2b 

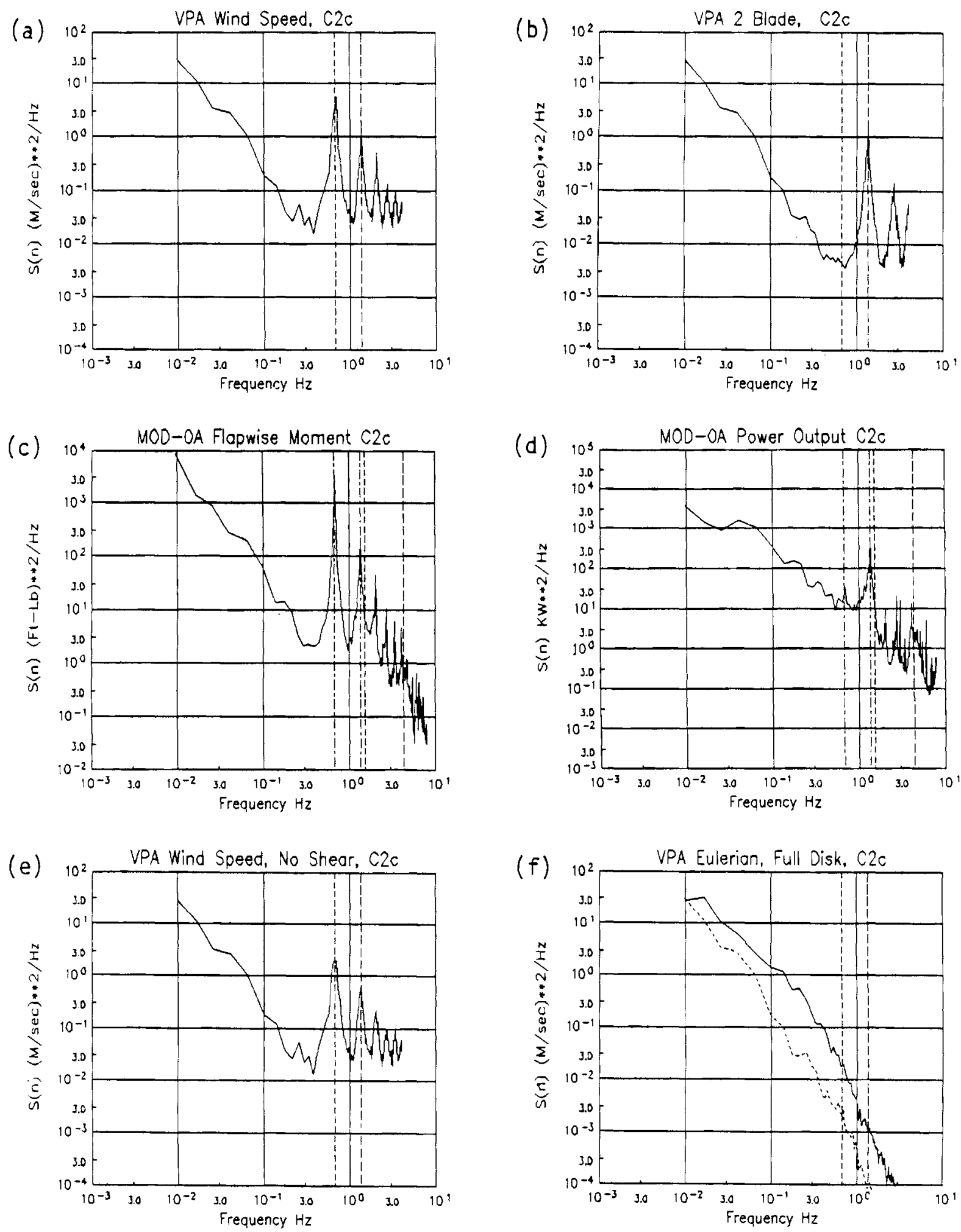

FIGURE 11. Complete Set of Spectral Plots for Case C2c 

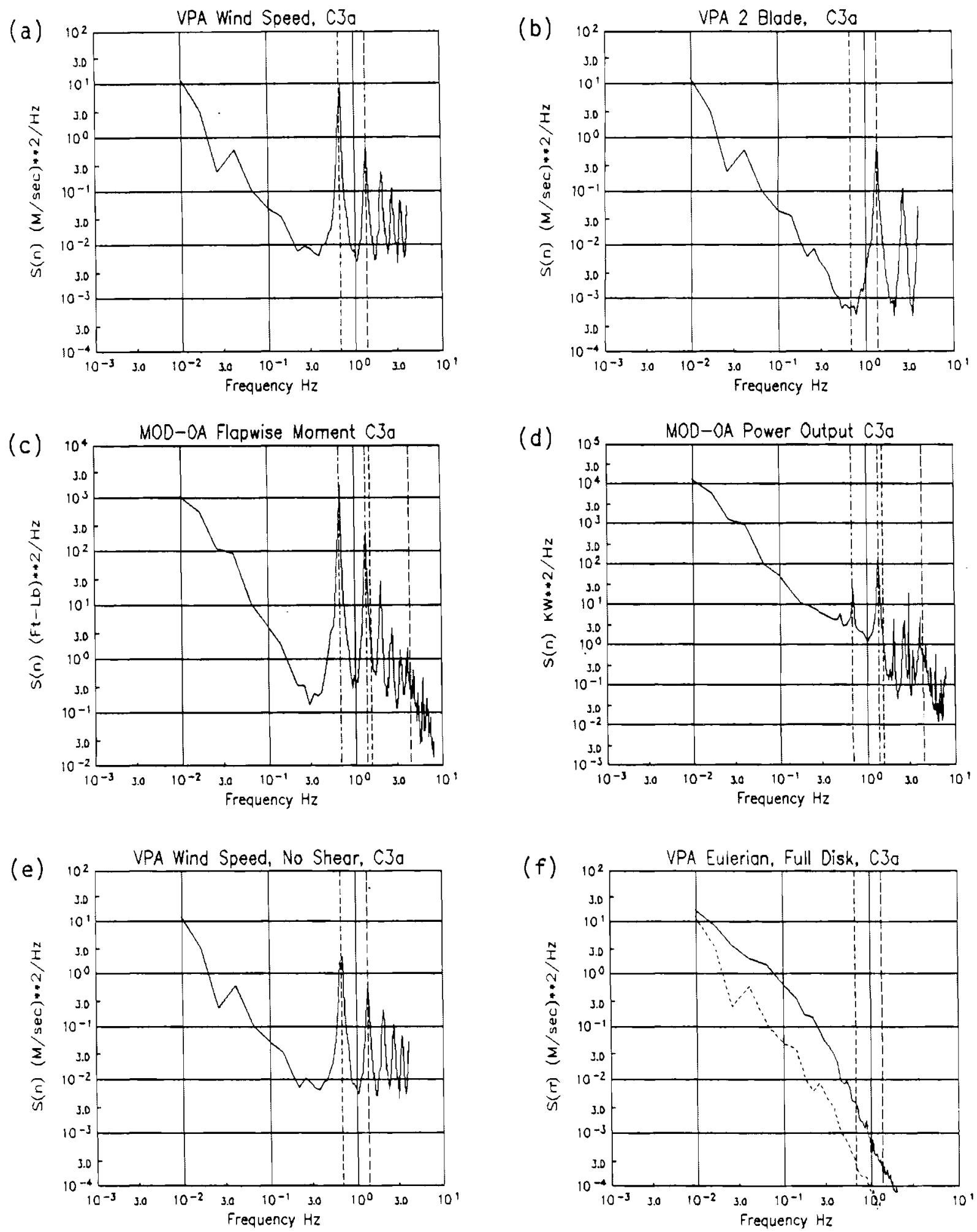

FIGURE 12. Complete Set of Spectral Plots for Case C3a 

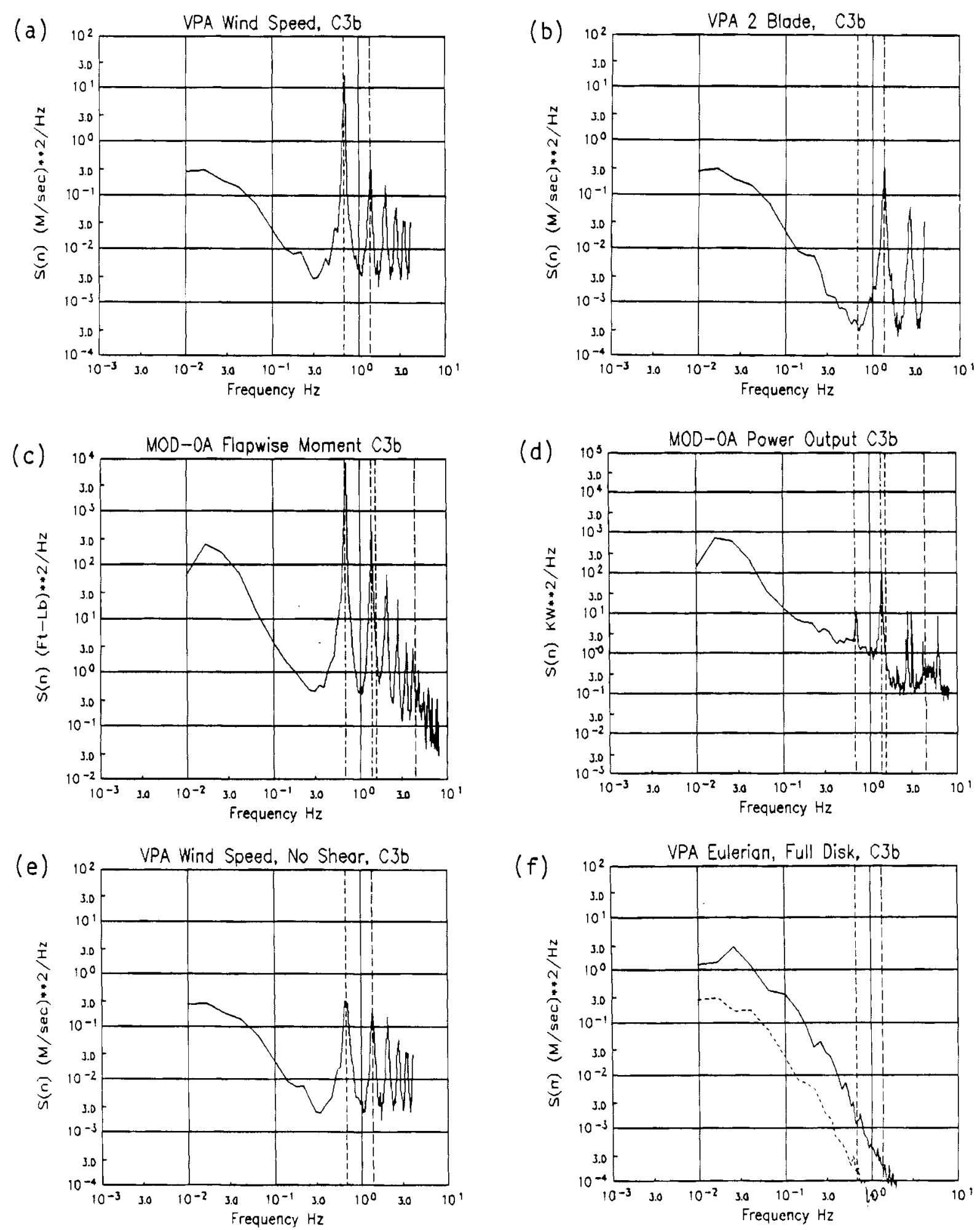

FIGURE 13. Complete Set of Spectral Plots for Case C3b 

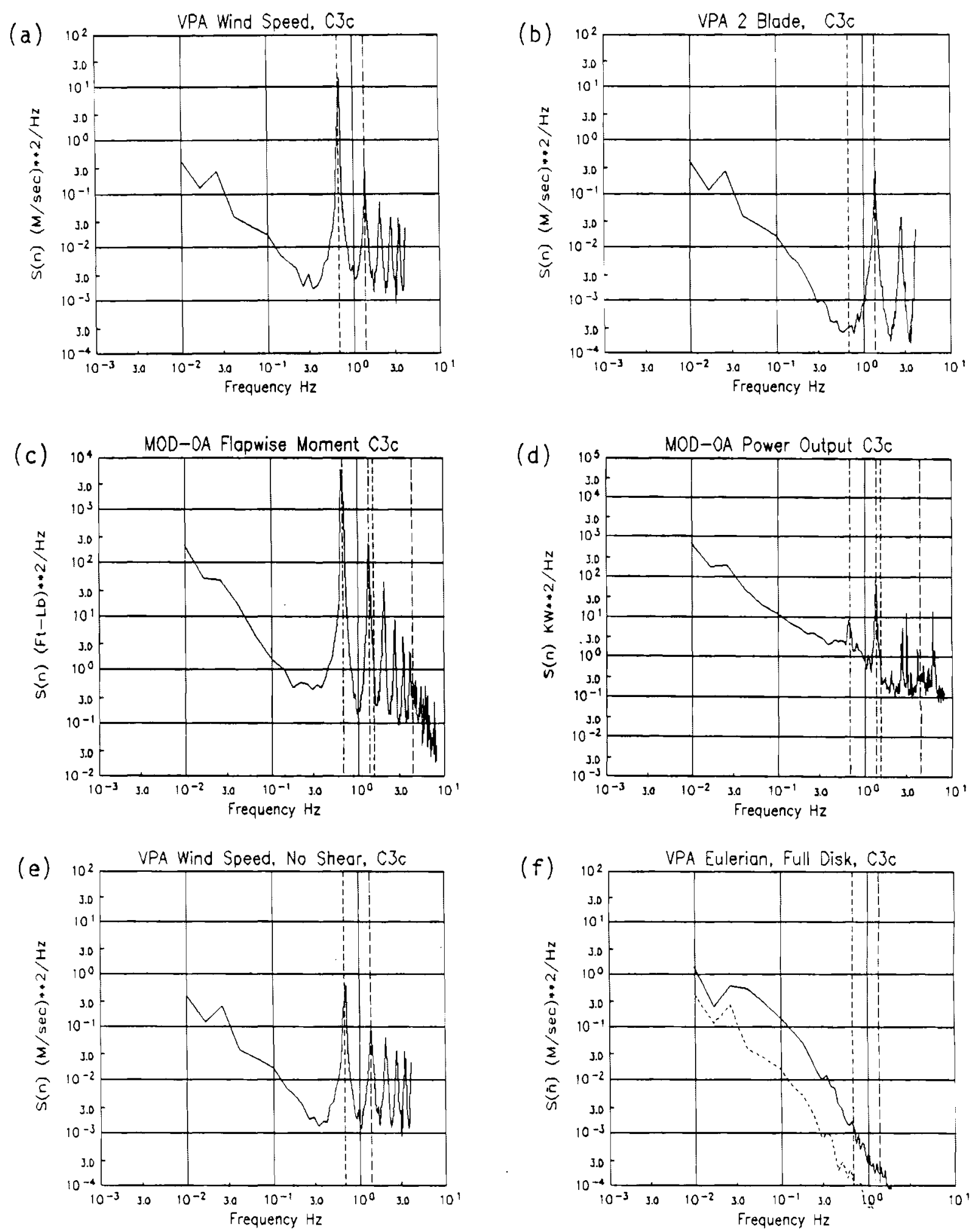

FIGURE 14. Complete Set of Spectral Plots for Case C3C 

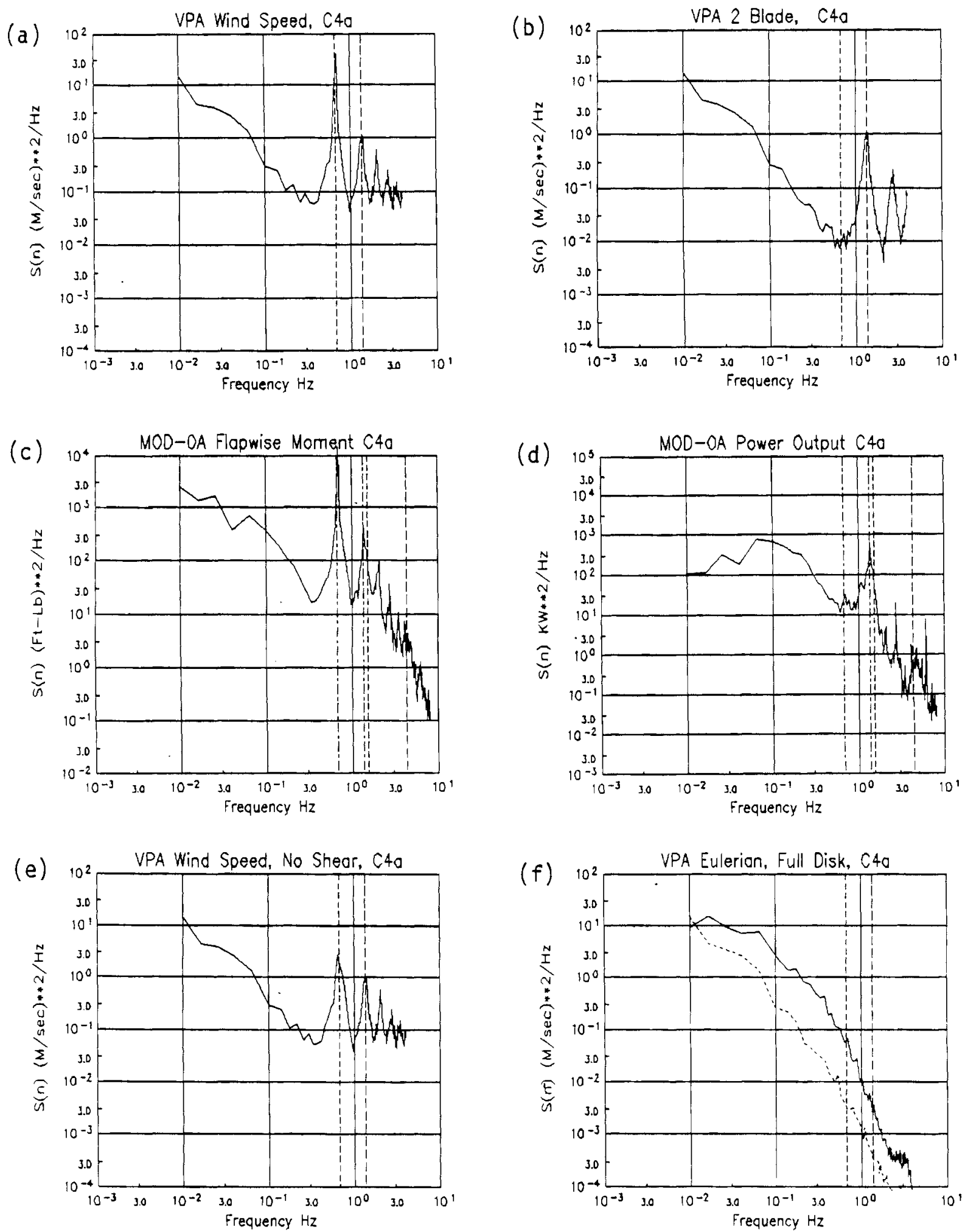

FIGURE 15. Complete Set of Spectral Plats for Case C4a 
(a)

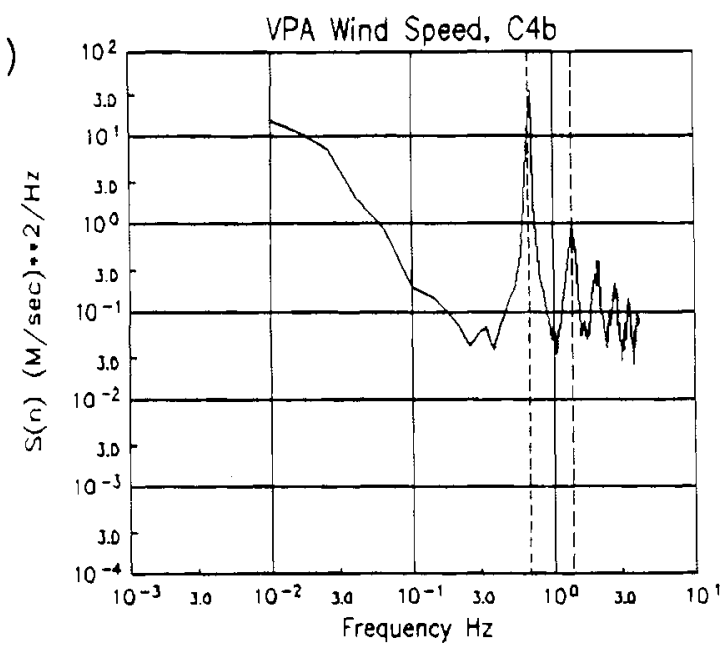

(c)

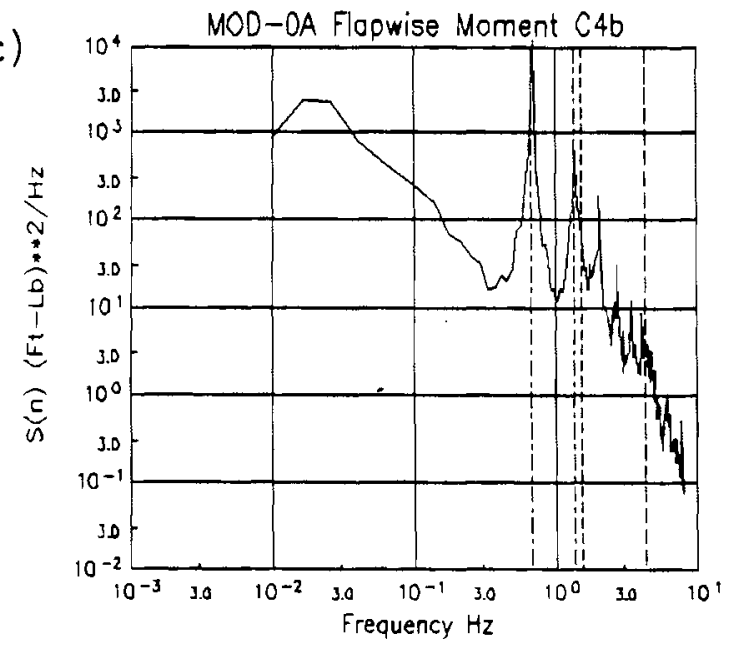

(e) $10^{2} \quad$ VPA Wind Speed. No Sheor, C4b

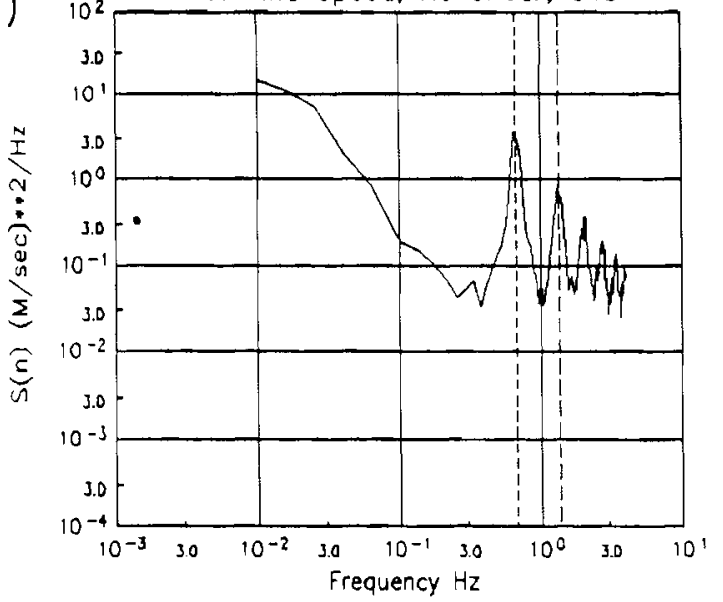

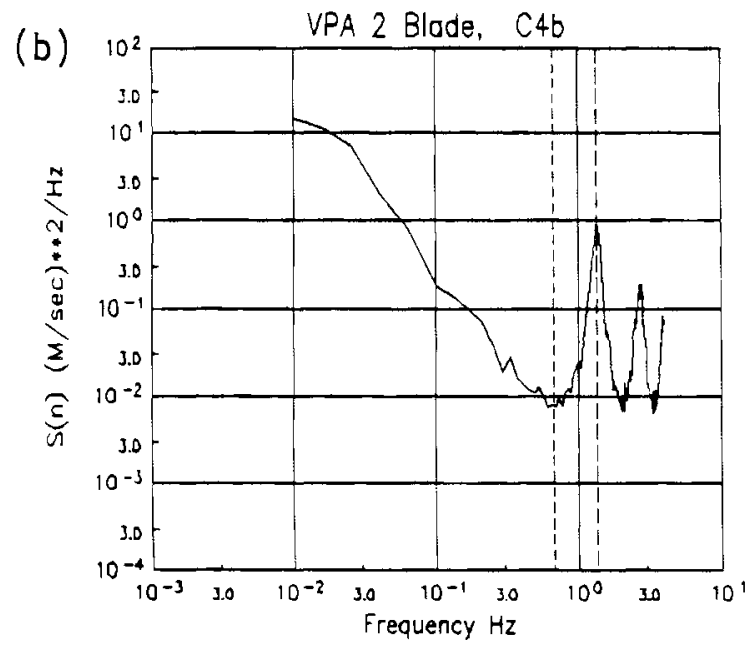

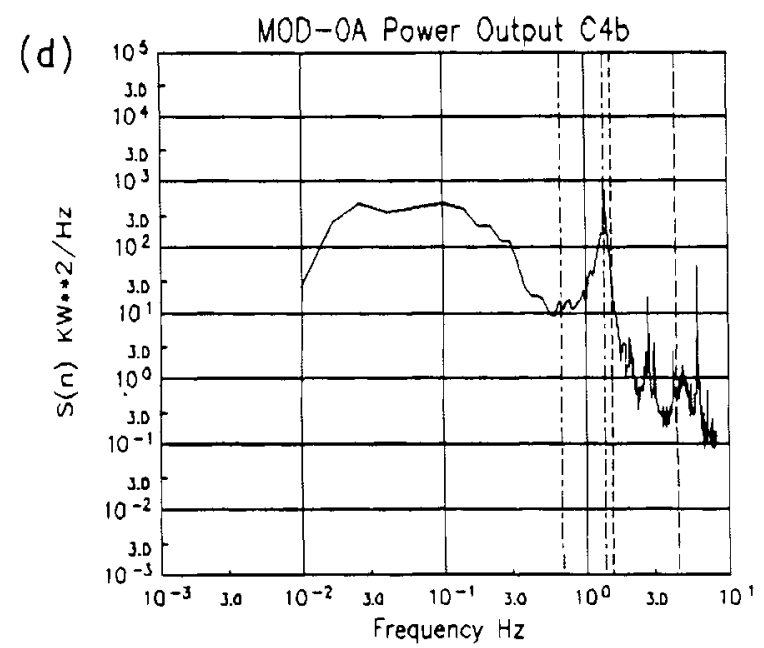

(f) $10^{2} \quad$ VPA Eulerion, Full Disk, C46

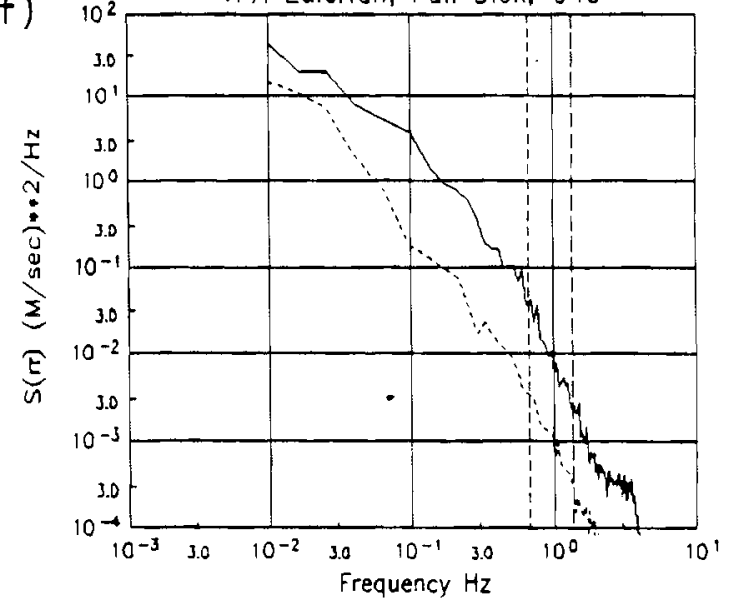

FIGURE 16. Complete Set of Spectral Plots for Case C4b 

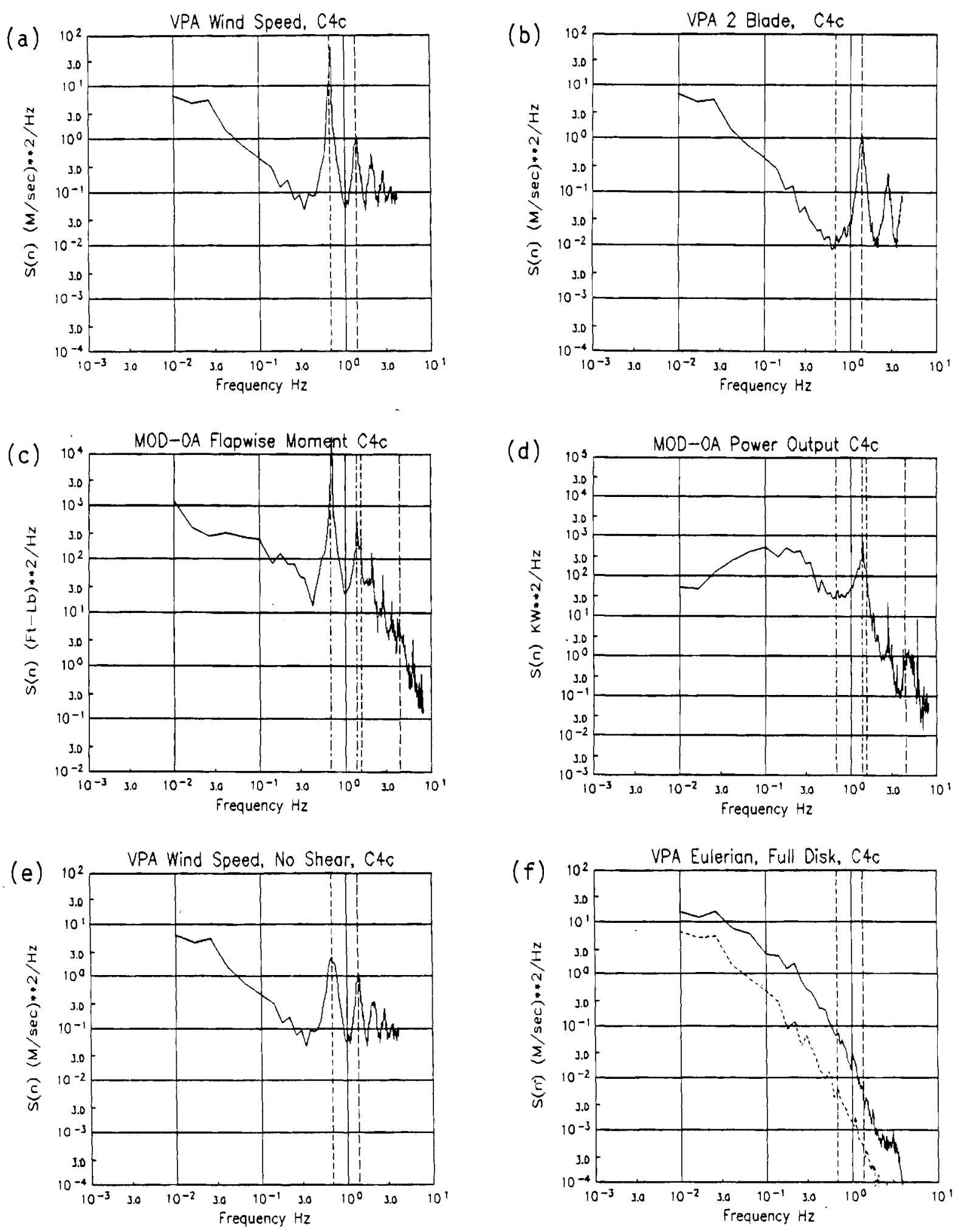

FIGURE 17. Complete Set of Spectral Plots for Case C4c 
which are not repeated from one revolution of the blade to the next one $1.5 \mathrm{~s}$ later. This is confirmed by the Eulerian spectra in part $f$ of each figure, which shows more energy at the $1 P$ frequency. Cases $C 2 a$ and $C 2 c$ show a greater difference between the VPA and no-shear data, visible in the IP and a little in the 2P spike. Case C2b showed very little difference between the VPA and no-shear data, since it had very low shear.

The blade flapwise and power spectra for cases $c 2$ (parts $c$ and d, Figures 9, 10 and 11) show substantial effects caused by the blade pitch control system, which was controlling the power to $200 \mathrm{~kW}$ during these cases. The power output spectra in Figures $10 \mathrm{~d}$ and $11 \mathrm{~d}$ have greatly reduced energy at low frequencies and enhanced energy at 0.1 to $0.5 \mathrm{~Hz}$, when compared with the low frequency wind spectra. Case C2a (Figure 9d) shows less of this effect, because the turbine was not above rated power the whole time. The flapwise bending moment spectra have very sharp spikes; this is probably an effect of the tower shadow, which would tend to add energy to the spectrum at exactly the harmonic frequencies.

Case C3a was a slightly stable case. Its spectra are similar to those from cases $\mathrm{Cl}$, with the floor level slightly lower at $8 \times 10^{-3}$. The spikes are taller and narrower in both VPA winds and flapwise bending moment. A larger difference exists between the VPA and no shear spectra.

Cases C3b and c (Figures 13 and 14) are cases of low wind speed, low turbulence and, high shear. The VPA wind spectra have very low floor levels of 2 to $4 \times 10^{-3}$. The $1 P$ spike is by far the tallest in the VPA spectrum, due to the dominance of mean wind shear. Thus, the no-shear spectrum is drastically different, with most of the energy removed from $1 P$ and some from $2 P$. The wind speed in these cases was much more stationary than the neutral-unstable cases, such that the lowest frequencies have little spectral energy. This also results in a relatively flat power output spectrum.

The highest wind speed cases in our analysis are from the somewhat stable wind regime, C4. Spectra from these cases (Figures 15, 16 and 17) show more extreme effects of wind turbulence. The floor level is up to $8 \times 10^{-2}$, making the spikes broader and seemingly shorter, especially the $4 \mathrm{P}$ and $5 \mathrm{P}$ spikes. 
(The no-shear case differs from the VPA mostly in the 1P spike). This is again an effect of the wind speed, which creates greater changes in the rotationally sampled wind in the 1.5-s revolution time. This relationship between the spike and the floor level can also be thought of as a function of tip speed ratio. For a slower turning wind turbine, so that the tip speed ratio is lower, the floor level is also increased (George 1984).

The effects of pitch control on the wind turbine spectra are more apparent in these three high wind speed cases. The flapwise bending moment is now also controlled somewhat at low frequencies and enhanced in the $0.1-$ to $0.5-\mathrm{Hz}$ range. In the last case (Figure $17 \mathrm{C}$ ) this results in a negative spike at $0.5 \mathrm{~Hz}$, rather than a broad dip as in the lower wind speed cases. The spikes look small and sharp, with very high floor levels between them. The MOD-OA power-out spectra are also controlled to reduce low-frequency fluctuations and enhance the energy above $0.1 \mathrm{~Hz}$. The $2 \mathrm{P}$ spike is very broad but not high, and the spectral density drops off more than two orders of magnitude at frequencies higher than $1.5 \mathrm{~Hz}$.

\subsection{VARIANCE OF WIND SPEED DUE TO ROTATIONAL HARMONICS}

The plots of spectral estimates in this paper are of $S(n)$ versus $n$. The spectral density, $S(n)$, has the units of $\left(m^{2} / s^{2}\right) / H z$ for wind speed data. When $S(n)$ is integrated over a range of frequency, an estimate is obtained of the variance in the time series due to fluctuations whose frequencies fall within that range. If $n_{0}$ is the rotational frequency of the wind turbine rotor, then we define a variance $\sigma_{i}^{2}$ such that

$$
\sigma_{i}^{2}=\int_{(i-0.5) n_{0}}^{(i+0.5) n_{0}} \begin{gathered}
S(n) d n \\
\text { for } i=1,2,3,4,5
\end{gathered}
$$

is the variance associated with each harmonic of the rotational frequency (each "spike" on the rotationaliy sampled spectrum), and

$$
\sigma_{0}^{2}=\int_{0}^{0.5 n_{0}} S(n) d n
$$

is the variance due to low frequency wind fluctuations. 
Table 3 shows the sum of $\sigma_{i}{ }^{2}$ for the first five harmonics of the wins turbine rotor, for all cases. The variances are tabulated for the standard one-blade rotationally sampled time series, labeled VPA (part a in Figures 6 through 17), the one-blade time series with mean winds and shear removed (part $e$, Figures 6 through 17), and the variance due to the mean shear profile. For most cases, the latter two variances add up to the VPA variance to within $2 \%$. Generally, in $\mathrm{Cl}$ over $80 \%$ of the variance is present even after all mean shears are removed. Even for the higher wind speed, neutra1-to-unstable cases in $\mathrm{C2}$, $65 \%$ of the total variance is present in the no-shear data. For the highly stable cases C3b and $c$, very little turbulence is present in the wind, leading to very small variances in the no-shear case. In C3a, the slightly stable low-wind case, the variance is split evenly between the mean-shear and no-shear data. The high-wind, stable cases in $\mathrm{C} 4$ have relatively large amounts of variance in both the mean-shear and no-shear data, with about $30 \%$ of the total variance in the no-shear spectrum.

TABLE 3. Wind Speed Variance $\left(\mathrm{m}^{2} / \mathrm{s}^{2}\right)$ Summed for All Five Harmonic Spikes, Excluding Low Frequencies, for A11 Cases

\begin{tabular}{|c|c|c|c|c|}
\hline Case & $\begin{array}{c}\text { Wind } \\
\text { Speed, } \mathrm{m} / \mathrm{s}\end{array}$ & VPA & $\begin{array}{l}\text { VPA Mean } \\
\text { Removed }\end{array}$ & $\begin{array}{c}\text { Mean } \\
\text { Profile }\end{array}$ \\
\hline $\begin{array}{l}\text { Cla } \\
\text { C1b } \\
\text { Clc }\end{array}$ & $\begin{array}{l}7.66 \\
6.82 \\
7.68\end{array}$ & $\begin{array}{l}0.3921 \\
0.4019 \\
0.5244\end{array}$ & $\begin{array}{l}0.3464 \\
0.3259 \\
0.4284\end{array}$ & $\begin{array}{l}0.0429 \\
0.0739 \\
0.0869\end{array}$ \\
\hline $\begin{array}{l}\mathrm{C} 2 \mathrm{a} \\
\mathrm{C} 2 \mathrm{~b} \\
\mathrm{C} 2 \mathrm{c}\end{array}$ & $\begin{array}{r}9.87 \\
11.19 \\
10.71\end{array}$ & $\begin{array}{l}0.8915 \\
0.6089 \\
0.7151\end{array}$ & $\begin{array}{l}0.4569 \\
0.5117 \\
0.5013\end{array}$ & $\begin{array}{l}0.4263 \\
0.0817 \\
0.2278\end{array}$ \\
\hline $\begin{array}{l}\mathrm{C} 3 \mathrm{a} \\
\mathrm{C} 3 \mathrm{~b} \\
\mathrm{C} 3 \mathrm{c}\end{array}$ & $\begin{array}{l}5.95 \\
5.90 \\
5.70\end{array}$ & $\begin{array}{l}0.6319 \\
0.8177 \\
0.6948\end{array}$ & $\begin{array}{l}0.3097 \\
0.0961 \\
0.0683\end{array}$ & $\begin{array}{l}0.3179 \\
0.7093 \\
0.6232\end{array}$ \\
\hline $\begin{array}{l}c 4 a \\
c 4 b \\
c 4 c\end{array}$ & $\begin{array}{l}12.52 \\
12.32 \\
14.00\end{array}$ & $\begin{array}{l}2.5123 \\
2.2045 \\
3.2176\end{array}$ & $\begin{array}{l}0.8240 \\
0.7974 \\
0.8952\end{array}$ & $\begin{array}{l}1.7039 \\
1.4320 \\
2.4946\end{array}$ \\
\hline
\end{tabular}




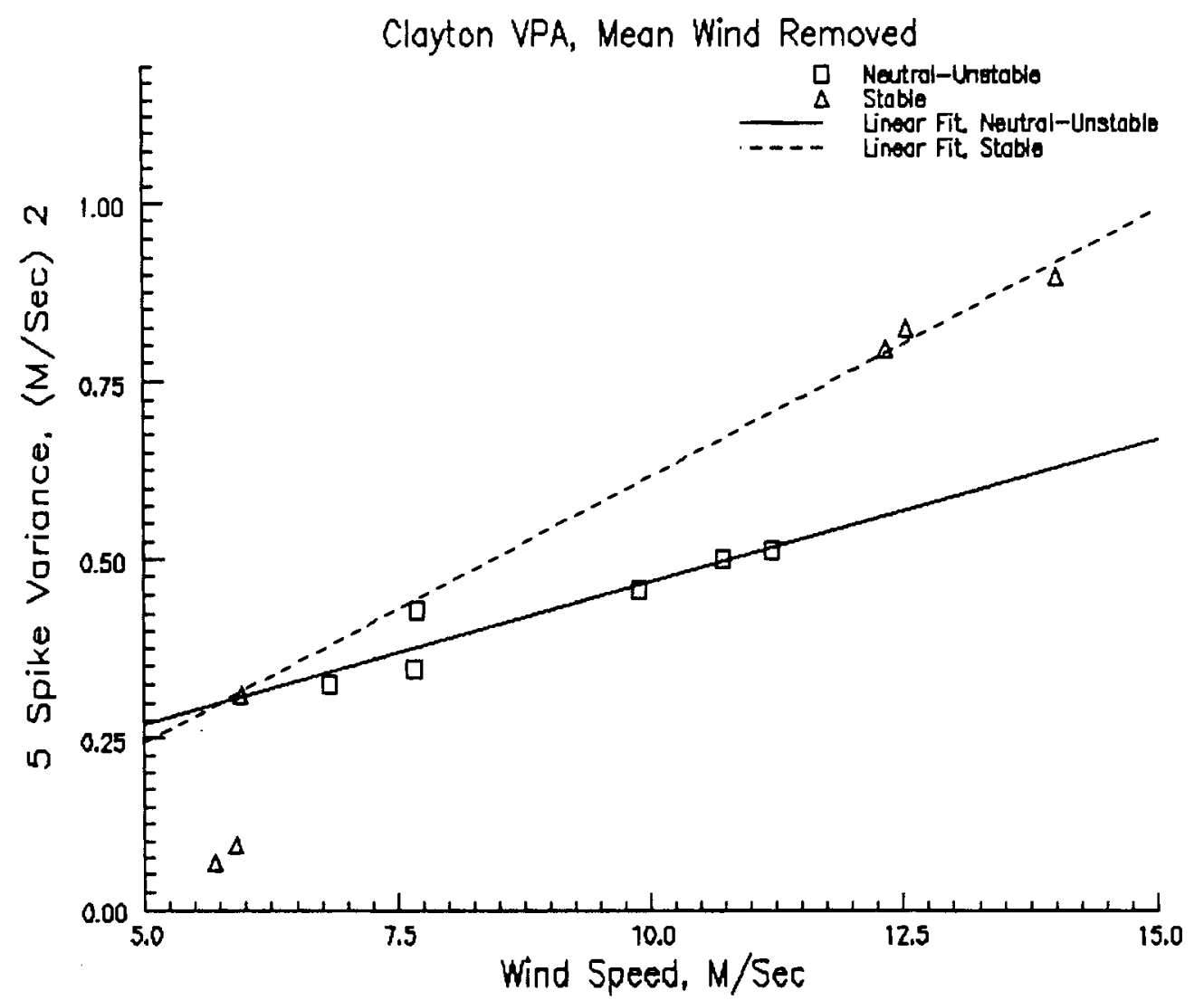

FIGURE 18. Sum of Variance in Five Harmonic Spikes, for A11 Cases. C1 and C2 marked with squares, $C 3$ and $C 4$ with triangles. Data have the mean wind removed at all points on the array.

The values of variance for the VPA data with no shear are plotted in Figure 18 as a function of wind speed for all cases. Squares denote neutral-tounstable cases ( $\mathrm{C} 1$ and $\mathrm{C} 2$ ), and triangles denote stable cases ( $\mathrm{C} 3$ and $\mathrm{C} 4$ ). The solid line is a least-squares linear fit to the six values in cases $\mathrm{Cl}$ and $\mathrm{C2}$. This line has the equation:

$$
\sum_{i=1}^{5} \sigma_{i}^{2}=0.072+0.040 w_{s}
$$

where $W_{S}$ is the mean wind speed for each case. Since the linear fit appears to be quite good, and since the neutral-to-unstable cases all have similar turbulence properties, this line may be a useful means of predicting the spike 
variance, for this size wind turbine only, given a known mean wind speed over a flat site. A dashed line is drawn as a linear fit to cases C3a and C4a, b and $c$, shown as triangles on the plot. This line has the equation:

$$
\sum_{i=1}^{5} \sigma_{i}^{2}=-0.130+0.075 w_{s} .
$$

Cases $c 3 b$ and $c$, which had almost no turbulence to generate this variance, obviously do not fit this pattern. C3a, a slightly stable, turbulent nighttime case, also falls on the regression line for the daytime neutral-to-unstable cases. The evidence for this linear relationship among the stable cases is weaker, due to a lack of data at different wind speeds.

The variance due to mean wind shear in Table 3 can be approximated as

$$
\sum_{i=1}^{5} \sigma_{i}^{2}=\left(\frac{\sqrt{2}}{4} \times \text { Total Shear }\right)^{2}
$$

where the total shear is the difference between the mean wind speed at the top of the disk and the bottom (see Table 2). We assume that the actual shear is close to linear across the disk of rotation. A better approximation can be obtained if a detailed wind shear profile is available, from a single meteorological tower or other vertically scanning sensor. By combining one of these shear estimates with the linear regression estimates of the variance due to turbulence as a function of wind speed, a rough estimate of the expected variance in the rotationally sampled wind, can be calculated for this particular site and array size.

The amount of variance at each harmonic is tabulated in Table 4 for cases C1 and $\mathrm{C2}$, and in Table 5 for cases $\mathrm{C} 3$ and C4. The large differences in lowfrequency variance from one case to the next are due to a lack of wind speed stationarity in some cases. The mean profile variances show that almost all the energy in the mean shear is concentrated at the IP frequency. The last two columns show the changes in variance for rotational time series in which 
TABLE 4. Wind Speed Variance $\left(\mathrm{m}^{2} / \mathrm{s}^{2}\right)$ in Each Harmonic Spike, Neutral-to-Unstable Cases C1 and C2

\begin{tabular}{|c|c|c|c|c|c|c|}
\hline Case & Harmonic & VPA & $\begin{array}{l}\text { VPA Mean } \\
\text { Removed }\end{array}$ & $\begin{array}{c}\text { Mean } \\
\text { Profile }\end{array}$ & $\begin{array}{l}\text { VPA } 5 \text { pt } \\
\text { Lopass }\end{array}$ & $\begin{array}{l}\text { VPA } 9 \text { pt } \\
\text { Lopass }\end{array}$ \\
\hline $\mathrm{Cla}$ & $\begin{array}{l}\text { Lo Freq } \\
\text { IP } \\
2 \mathrm{P} \\
3 \mathrm{P} \\
4 \mathrm{P} \\
5 \mathrm{P}\end{array}$ & $\begin{array}{l}0.833 \\
0.228 \\
0.082 \\
0.039 \\
0.025 \\
0.018\end{array}$ & $\begin{array}{l}0.821 \\
0.185 \\
0.081 \\
0.038 \\
0.025 \\
0.017\end{array}$ & $\begin{array}{l}0.000 \\
0.042 \\
0.001 \\
0.000 \\
0.000 \\
0.000\end{array}$ & $\begin{array}{l}0.829 \\
0.225 \\
0.080 \\
0.035 \\
0.023 \\
0.014\end{array}$ & $\begin{array}{l}0.828 \\
0.219 \\
0.075 \\
0.031 \\
0.020 \\
0.012\end{array}$ \\
\hline Clb & $\begin{array}{l}\text { Lo Freq } \\
\text { IP } \\
2 P \\
3 P \\
4 P \\
5 P\end{array}$ & $\begin{array}{l}0.952 \\
0.247 \\
0.077 \\
0.037 \\
0.023 \\
0.019\end{array}$ & $\begin{array}{l}0.938 \\
0.181 \\
0.071 \\
0.033 \\
0.022 \\
0.018\end{array}$ & $\begin{array}{l}0.000 \\
0.064 \\
0.005 \\
0.004 \\
0.000 \\
0.000\end{array}$ & $\begin{array}{l}0.948 \\
0.244 \\
0.073 \\
0.033 \\
0.020 \\
0.016\end{array}$ & $\begin{array}{l}0.944 \\
0.237 \\
0.068 \\
0.029 \\
0.017 \\
0.013\end{array}$ \\
\hline $\mathrm{Clc}$ & $\begin{array}{l}\text { Lo Freq } \\
1 P \\
2 P \\
3 P \\
4 P \\
5 P\end{array}$ & $\begin{array}{l}0.269 \\
0.310 \\
0.102 \\
0.055 \\
0.033 \\
0.025\end{array}$ & $\begin{array}{l}0.264 \\
0.229 \\
0.091 \\
0.052 \\
0.033 \\
0.024\end{array}$ & $\begin{array}{l}0.000 \\
0.075 \\
0.008 \\
0.004 \\
0.000 \\
0.000\end{array}$ & $\begin{array}{l}0.268 \\
0.303 \\
0.095 \\
0.051 \\
0.028 \\
0.020\end{array}$ & $\begin{array}{l}0.264 \\
0.295 \\
0.088 \\
0.045 \\
0.023 \\
0.015\end{array}$ \\
\hline $\mathrm{C} 2 \mathrm{a}$ & $\begin{array}{l}\text { Lo Freq } \\
\text { 1P } \\
2 P \\
3 P \\
4 P \\
5 P\end{array}$ & $\begin{array}{l}0.283 \\
0.631 \\
0.128 \\
0.060 \\
0.042 \\
0.030\end{array}$ & $\begin{array}{l}0.278 \\
0.225 \\
0.102 \\
0.059 \\
0.041 \\
0.030\end{array}$ & $\begin{array}{l}0.000 \\
0.402 \\
0.024 \\
0.000 \\
0.000 \\
0.000\end{array}$ & $\begin{array}{l}0.278 \\
0.620 \\
0.121 \\
0.054 \\
0.035 \\
0.024\end{array}$ & $\begin{array}{l}0.272 \\
0.608 \\
0.113 \\
0.047 \\
0.029 \\
0.019\end{array}$ \\
\hline $\mathrm{C} 2 \mathrm{~b}$ & $\begin{array}{l}\text { Lo Freq } \\
1 \mathrm{P} \\
2 \mathrm{P} \\
3 \mathrm{P} \\
4 \mathrm{P} \\
5 \mathrm{P}\end{array}$ & $\begin{array}{l}0.598 \\
0.371 \\
0.104 \\
0.062 \\
0.040 \\
0.032\end{array}$ & $\begin{array}{l}0.590 \\
0.284 \\
0.101 \\
0.058 \\
0.038 \\
0.031\end{array}$ & $\begin{array}{l}0.000 \\
0.076 \\
0.002 \\
0.002 \\
0.002 \\
0.000\end{array}$ & $\begin{array}{l}0.594 \\
0.362 \\
0.094 \\
0.054 \\
0.033 \\
0.026\end{array}$ & $\begin{array}{l}0.587 \\
0.350 \\
0.083 \\
0.046 \\
0.027 \\
0.021\end{array}$ \\
\hline $\mathrm{C} 2 \mathrm{c}$ & $\begin{array}{l}\text { Lo Freq } \\
1 \mathrm{P} \\
2 \mathrm{P} \\
3 \mathrm{P} \\
4 \mathrm{P} \\
5 \mathrm{P}\end{array}$ & $\begin{array}{l}0.498 \\
0.431 \\
0.146 \\
0.070 \\
0.037 \\
0.032\end{array}$ & $\begin{array}{l}0.490 \\
0.264 \\
0.114 \\
0.057 \\
0.035 \\
0.031\end{array}$ & $\begin{array}{l}0.000 \\
0.169 \\
0.039 \\
0.015 \\
0.004 \\
0.000\end{array}$ & $\begin{array}{l}0.489 \\
0.421 \\
0.137 \\
0.063 \\
0.030 \\
0.024\end{array}$ & $\begin{array}{l}0.480 \\
0.406 \\
0.125 \\
0.054 \\
0.024 \\
0.018\end{array}$ \\
\hline
\end{tabular}


TABLE 5. Wind Speed Variance $\left(\mathrm{m}^{2} / \mathrm{s}^{2}\right)$ in Each

Harmonic Spike, Stable Cases C3 and C4

\begin{tabular}{|c|c|c|c|c|c|c|}
\hline Case & Harmonic & VPA & $\begin{array}{l}\text { VPA Mean } \\
\text { Removed }\end{array}$ & $\begin{array}{l}\text { Mean } \\
\text { Profile }\end{array}$ & $\begin{array}{l}\text { VPA } 5 \text { pt } \\
\text { Lopass }\end{array}$ & $\begin{array}{l}\text { VPA } 9 \text { pt } \\
\text { Lopass }\end{array}$ \\
\hline C3a & $\begin{array}{l}\text { Lo Freq } \\
1 P \\
2 P \\
3 P \\
4 P \\
5 P\end{array}$ & $\begin{array}{l}0.204 \\
0.481 \\
0.074 \\
0.036 \\
0.024 \\
0.017\end{array}$ & $\begin{array}{l}0.200 \\
0.172 \\
0.064 \\
0.034 \\
0.023 \\
0.017\end{array}$ & $\begin{array}{l}0.000 \\
0.306 \\
0.010 \\
0.001 \\
0.001 \\
0.000\end{array}$ & $\begin{array}{l}0.202 \\
0.478 \\
0.071 \\
0.033 \\
0.022 \\
0.015\end{array}$ & $\begin{array}{l}0.200 \\
0.474 \\
0.068 \\
0.030 \\
0.019 \\
0.013\end{array}$ \\
\hline$c 3 b$ & $\begin{array}{l}\text { Lo Freq } \\
1 \mathrm{P} \\
2 \mathrm{P} \\
3 \mathrm{P} \\
4 \mathrm{P} \\
5 \mathrm{P}\end{array}$ & $\begin{array}{l}0.018 \\
0.740 \\
0.036 \\
0.019 \\
0.012 \\
0.010\end{array}$ & $\begin{array}{l}0.018 \\
0.033 \\
0.024 \\
0.018 \\
0.012 \\
0.010\end{array}$ & $\begin{array}{l}0.000 \\
0.698 \\
0.011 \\
0.000 \\
0.000 \\
0.000\end{array}$ & $\begin{array}{l}0.018 \\
0.741 \\
0.036 \\
0.018 \\
0.011 \\
0.009\end{array}$ & $\begin{array}{l}0.017 \\
0.739 \\
0.034 \\
0.016 \\
0.010 \\
0.008\end{array}$ \\
\hline$c 3 c$ & $\begin{array}{l}\text { Lo Freq } \\
1 P \\
2 P \\
3 P \\
4 P \\
5 P\end{array}$ & $\begin{array}{l}0.024 \\
0.645 \\
0.028 \\
0.009 \\
0.007 \\
0.006\end{array}$ & $\begin{array}{l}0.023 \\
0.036 \\
0.012 \\
0.008 \\
0.006 \\
0.006\end{array}$ & $\begin{array}{l}0.000 \\
0.606 \\
0.016 \\
0.001 \\
0.000 \\
0.000\end{array}$ & $\begin{array}{l}0.024 \\
0.645 \\
0.028 \\
0.009 \\
0.006 \\
0.006\end{array}$ & $\begin{array}{l}0.023 \\
0.645 \\
0.027 \\
0.008 \\
0.006 \\
0.005\end{array}$ \\
\hline $\mathrm{C} 4 \mathrm{a}$ & $\begin{array}{l}\text { Lo Freq } \\
1 \mathrm{P} \\
2 \mathrm{P} \\
3 \mathrm{P} \\
4 \mathrm{P} \\
5 \mathrm{P}\end{array}$ & $\begin{array}{l}0.308 \\
2.023 \\
0.232 \\
0.119 \\
0.078 \\
0.061\end{array}$ & $\begin{array}{l}0.301 \\
0.347 \\
0.226 \\
0.115 \\
0.076 \\
0.060\end{array}$ & $\begin{array}{l}0.001 \\
1.098 \\
0.002 \\
0.002 \\
0.001 \\
0.000\end{array}$ & $\begin{array}{l}0.298 \\
1.993 \\
0.216 \\
0.106 \\
0.062 \\
0.047\end{array}$ & $\begin{array}{l}0.287 \\
1.964 \\
0.195 \\
0.090 \\
0.048 \\
0.034\end{array}$ \\
\hline $\mathrm{C} 4 \mathrm{~b}$ & $\begin{array}{l}\text { Lo Freq } \\
1 \mathrm{P} \\
2 \mathrm{P} \\
3 \mathrm{P} \\
4 \mathrm{P} \\
5 \mathrm{P}\end{array}$ & $\begin{array}{l}0.547 \\
1.800 \\
0.185 \\
0.104 \\
0.067 \\
0.049\end{array}$ & $\begin{array}{l}0.540 \\
0.410 \\
0.172 \\
0.102 \\
0.066 \\
0.048\end{array}$ & $\begin{array}{l}0.000 \\
1.420 \\
0.010 \\
0.001 \\
0.001 \\
0.000\end{array}$ & $\begin{array}{l}0.542 \\
1.779 \\
0.171 \\
0.090 \\
0.057 \\
0.038\end{array}$ & $\begin{array}{l}0.534 \\
1.758 \\
0.154 \\
0.076 \\
0.047 \\
0.030\end{array}$ \\
\hline $\mathrm{C} 4 \mathrm{C}$ & $\begin{array}{l}\text { Lo Freq } \\
1 \mathrm{P} \\
2 \mathrm{P} \\
3 \mathrm{P} \\
4 \mathrm{P} \\
5 \mathrm{P}\end{array}$ & $\begin{array}{l}0.281 \\
2.811 \\
0.228 \\
0.134 \\
0.084 \\
0.062\end{array}$ & $\begin{array}{l}0.277 \\
0.407 \\
0.221 \\
0.125 \\
0.082 \\
0.060\end{array}$ & $\begin{array}{l}0.001 \\
2.484 \\
0.003 \\
0.005 \\
0.001 \\
0.000\end{array}$ & $\begin{array}{l}0.266 \\
2.809 \\
0.209 \\
0.112 \\
0.065 \\
0.047\end{array}$ & $\begin{array}{l}0.254 \\
2.785 \\
0.187 \\
0.093 \\
0.049 \\
0.034\end{array}$ \\
\hline
\end{tabular}


the individual anemometers have been digitally filtered before being rotationally sampled. The utility of these data for wind turbine correlations will be shown in the next chapter.

Another parameter that may be of interest is the rate at which the spike variance decreases with increasing frequency. In Figure 19, the variance due to each spike is plotted versus frequency on a log-log plot. Most of the traces on this plot seem to be linear. The equation of a straight line on a log-log plot has the form:

$$
\sigma_{i}^{2}=k_{0}\left(i n_{0}\right)^{k}
$$

where $K_{0}$ is the value for $\sigma_{i}^{2}$ at $n=1.0 \mathrm{~Hz}$ and $K_{1}$ is the slope of the line. In Table 6 , the values of $k_{0}$ and $k_{1}$ for a linear curve fit to each case are shown, along with the correlation coefficient for a linear regression of $\log \left(\sigma_{i}{ }^{2}\right)$

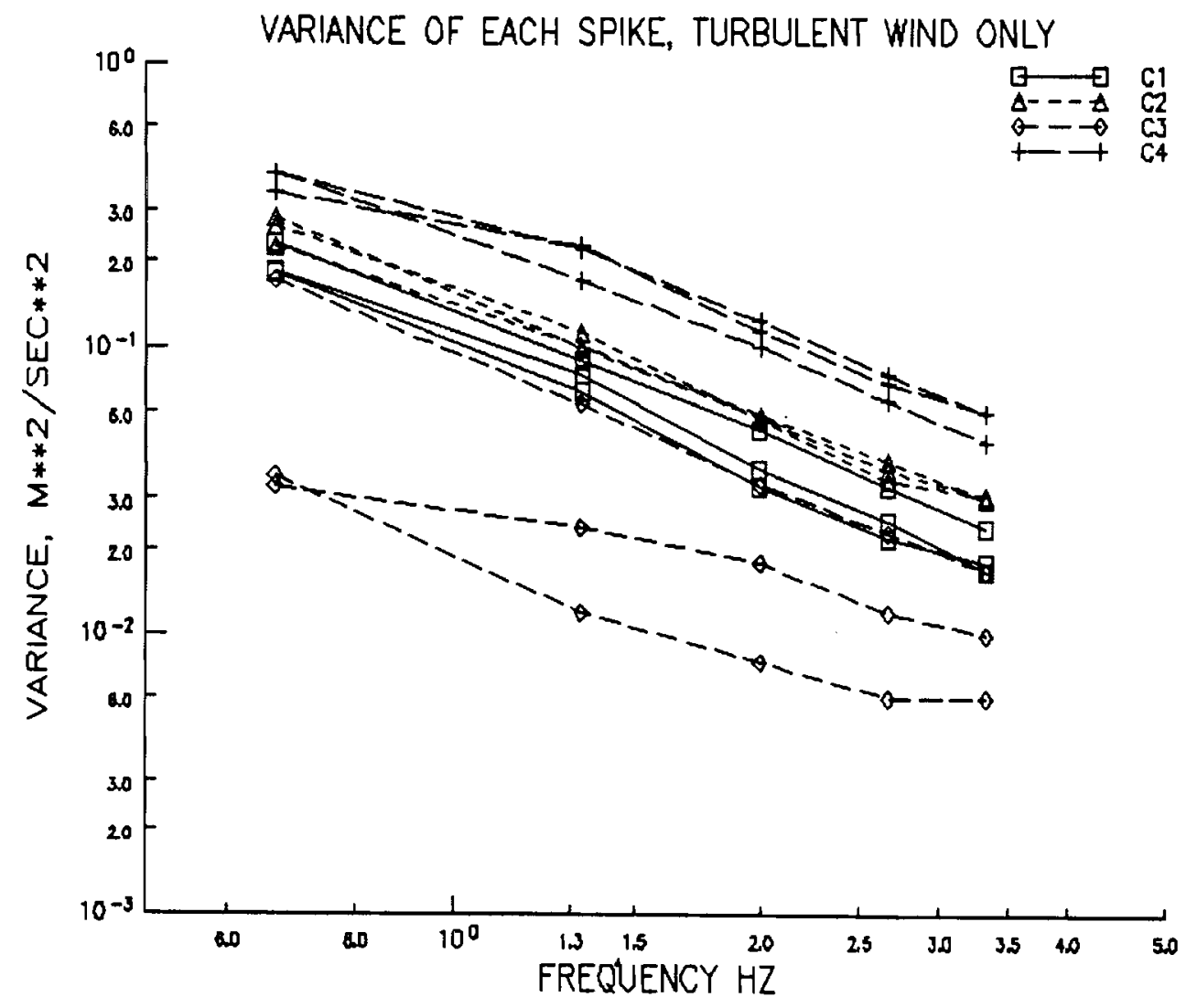

FIGURE 19. Variance in Each Harmonic Spike, for All Cases. Data have mean wind removed. 
TABLE 6. Logarithmic Curve Fit Parameters

for Harmonic Variances, 12 Cases

\begin{tabular}{|c|c|c|c|c|c|c|}
\hline $\begin{array}{c}\text { Case } \\
\# \\
\end{array}$ & Date & $\begin{array}{c}\text { Time, } \\
\text { MST } \\
\end{array}$ & $\begin{array}{l}\text { Mean wind } \\
\text { Speed, m/s }\end{array}$ & $\mathrm{K}_{0}, \mathrm{~m}^{2} / \mathrm{s}^{2}$ & $\mathrm{~K}_{1}$ & Correlation \\
\hline $\begin{array}{l}\text { Cla } \\
\text { Clb } \\
\text { Clc }\end{array}$ & $\begin{array}{l}11 / 25 / 81 \\
06 / 28 / 82 \\
06 / 28 / 82\end{array}$ & $\begin{array}{l}1211 \\
1350 \\
0818\end{array}$ & $\begin{array}{l}7.66 \\
6.82 \\
7.68\end{array}$ & $\begin{array}{l}0.109 \\
0.100 \\
0.133\end{array}$ & $\begin{array}{l}-1.50 \\
-1.49 \\
-1.40\end{array}$ & $\begin{array}{l}-0.996 \\
-0.997 \\
-1.000\end{array}$ \\
\hline $\begin{array}{l}\mathrm{C} 2 \mathrm{a} \\
\mathrm{C} 2 \mathrm{~b} \\
\mathrm{C} 2 \mathrm{c}\end{array}$ & $\begin{array}{l}01 / 01 / 82 \\
12 / 04 / 81 \\
06 / 30 / 82\end{array}$ & $\begin{array}{l}1231 \\
1303 \\
1740\end{array}$ & $\begin{array}{r}9.87 \\
11.19 \\
10.71\end{array}$ & $\begin{array}{l}0.140 \\
0.156 \\
0.155\end{array}$ & $\begin{array}{l}-1.25 \\
-1.40 \\
-1.40\end{array}$ & $\begin{array}{l}-0.999 \\
-.0999 \\
-0.995\end{array}$ \\
\hline $\begin{array}{l}\text { C3a } \\
\text { C3b } \\
\text { C3c }\end{array}$ & $\begin{array}{l}07.01 / 82 \\
12 / 18 / 81 \\
12 / 14 / 81\end{array}$ & $\begin{array}{l}0124 \\
1608 \\
1624\end{array}$ & $\begin{array}{l}5.95 \\
5.90 \\
5.70\end{array}$ & $\begin{array}{l}0.096 \\
0.027 \\
0.020\end{array}$ & $\begin{array}{l}-1.45 \\
-0.75 \\
-1.15\end{array}$ & $\begin{array}{l}-1.000 \\
-0.975 \\
-0.978\end{array}$ \\
\hline $\begin{array}{l}c 4 a \\
c 4 b \\
c 4 c\end{array}$ & $\begin{array}{l}01 / 01 / 82 \\
01 / 01 / 82 \\
01 / 01 / 82\end{array}$ & $\begin{array}{l}1803 \\
1546 \\
1825\end{array}$ & $\begin{array}{l}12.52 \\
12.32 \\
14.00\end{array}$ & $\begin{array}{l}0.249 \\
0.246 \\
0.273\end{array}$ & $\begin{array}{l}-1.14 \\
-1.33 \\
-1.20\end{array}$ & $\begin{array}{l}-0.982 \\
-0.999 \\
-0.993\end{array}$ \\
\hline
\end{tabular}

versus $\log \left(i n_{0}\right)$. The data in Figure 19 and Table 6 are for the rotationally sampled wind with the mean shear removed.

The two low turbulence cases, $\mathrm{C} 3 \mathrm{~b}$ and $\mathrm{C} 3 \mathrm{c}$, do not follow the pattern. Of the 10 turbulent cases, there is some tendency for a decrease in slope with increasing wind speed.

It may be we11 to emphasize that the results presented in this chapter apply only at the Clayton site, for wind turbines of the MOD-OA rotor size and hub height. Generally, based on our previous experience with turbulent wind, we would expect the energy in the harmonic spikes to be about the same for this size turbine at other flat sites. We expect greater energy for larger wind turbine rotors and less for smaller rotors. The spectral energy will be greater for lower hub heights and less for higher hub heights. The effect of complex terrain is unknown, but will probably result in higher variances. Also, the complex vertical wind shear profiles associated with complex terrain will require more levels of anemometry (at least four levels) to define the mean wind shear profile with enough detail to give reliable variance estimates.

In this chapter, we have presented the analysis of 12 cases of VPA and MOD-OA data, using spectral techniques. We have shown some predictable characteristics of these spectra for different wind speeds and stabilities. 
In the next chapter, we combine our knowledge of rotational sampling and the MOD-OA wind turbine into transfer function correlations between the VPA rotationally sampled wind and the MOD-OA blade bending moment. 


\section{.}




\subsection{COMPARISON OF MOD-OA BLADE BENDING MOMENT WITH VPA WINDS}

We have demonstrated, using spectral techniques, the high qualitative correlation between the VPA rotationally sampled wind speed and the MOD-OA blade flapwise root bending moment. In this chapter, we will regard the VPA wind data as a simple model of the forcing of the blade, and use the observed transfer function between this model wind and the bending moment response to assess both the model wind and the damping characteristics of the MOD-OA fiberglass blade.

\subsection{TRANSFER FUNCTION CALCULATIONS}

We chose the MOD-OA flapwise bending moment as our response parameter. It should respond linearly to the axial wind speed. The frequency response of the fiberglass blade was measured on a static test bed at the NASA-Lewis Research Center (Sullivan 1983). The first two natural frequencies were determined to be $1.5 \mathrm{~Hz}$ and $4.3 \mathrm{~Hz}$. Since the blade was weighted to simulate the mean stress under operating conditions, these frequencies should be the correct resonant frequencies seen under operating conditions, neglecting the "centrifugal" stiffening effect, which we do not estimate. The damping coefficient for the first harmonic was measured to be 0.008 , during the same test. However, this measurement was not considered by Sullivan to be a useful indication of the damping experienced by the operating turbine blade. For the present study, the measured resonant frequencies were taken as correct, and the damping coefficient was estimated by analysis of the measured response function of a rotor blade of the rotating MOD-OA.

The transfer function model for the blade is

$$
H_{b}(n)=\frac{1}{\sqrt{\left(1-\left(\frac{n}{n_{1}}\right)^{2}\right)^{2}+\left(2 z_{1} \frac{n}{n_{1}}\right)^{2}} \sqrt{\left(1-\left(\frac{n}{n_{2}}\right)^{2}\right)^{2}+\left(2 z_{2} \frac{n}{n_{2}}\right)^{2}}}
$$

where $n$ is the frequency, $n_{1}$ and $n_{2}$ are the first and second harmonic frequencies, and $z_{1}$ and $z_{2}$ are the first and second damping coefficients. 
From spectral measurements, we compute a corresponding transfer function

$$
H(n)=\sqrt{S_{t}(n) / S_{\text {rot }}}{ }^{(n)}
$$

where $S_{t}(n)$ is the spectral density function of the blade flapwise bending moment and $S_{\text {rot }}(n)$ is the corresponding spectral density of the rotationally sampled wind. In practice, we normalize $H(n)$ by the average value of $H(n)$ over low frequencies $(0$ to $0.33 \mathrm{~Hz}$ ). This will give us a value of 1.0 for both $H(n)$ and $H_{b}(n)$ at low frequencies, allowing us to compare the two directly.

One deviation of the blade response from $H_{b}(n)$ we expect in below-rated cases would be the presence of a small amount of chordwise force in the flapwise data, due to small twists in the blade. The average blade pitch angle for below-rated cases was $4^{\circ}$. In addition, the rotor coning results in a sinusoidal gravitational component, giving rise to enhanced IP energy in the flapwise spectrum.

The remaining deviation of the observed transfer function $H(n)$ from $H_{b}(n)$ is caused by shortcomings in the model input wind spectrum $S_{\text {rot }}(n)$. These include

- The wind data are point-sampled from a ring with the same diameter as the tip of the wind turbine blade. A more realistic wind input model would include the wind integrated over some finite portion of the length of the blade. The VPA data show slightly larger horizontal and vertical shears across the disk than would be expected from a blade-integrated wind input. The expected effect should be increased energy in the harmonic spikes of the rotationally sampled wind spectrum, relative to the flapwise bending moment response.

- The wind input data do not include effects from the "tower shadow", the wake of the wind turbine tower through which the downwind blades must rotate. The tower shadow should create enhanced spectral energy in the harmonics for the blade flapwise bending moment. The tower shadow thus results in decreased energy in the harmonic spikes for the wind spectrum relative to the bending moment spectrum, an effect opposite to that of the blade-tip sampling effect. 
- Additional wake effects may be due to large yaw errors and large fluctuations in wind direction, which may create wake effects from the nacelle itself. While the data were chosen to minimize this problem, it may be important for data cases with high mean yaw error and highly fluctuating wind directions (see Table 7).

- Noise that may exist in the measurements from which the spectra were calculated is not well eliminated by the method of calculating $H(n)$ used in this work.

TABLE 7. Summary of Wind Direction and MOD-OA Wind Turbine Characteristics of 12 Data Cases Used in VPA Analyses

\begin{tabular}{|c|c|c|c|c|c|c|c|}
\hline $\begin{array}{c}\text { Case } \\
\# \\
\end{array}$ & Date & $\begin{array}{l}\text { Time, } \\
\text { MST } \\
\end{array}$ & $\begin{array}{c}\text { Direction, } \\
\text { Degrees } \\
\end{array}$ & $\begin{array}{c}\sigma \theta, \\
\text { Degrees } \\
\end{array}$ & $\begin{array}{c}\text { Yaw Error, } \\
\text { Degrees } \\
\end{array}$ & $\begin{array}{c}\text { Tip Speed } \\
\text { Ratio } \\
\end{array}$ & $\begin{array}{l}\text { MOD-OA } \\
\text { Power, kW }\end{array}$ \\
\hline $\begin{array}{l}\text { Cla } \\
\text { clb } \\
\text { Clc }\end{array}$ & $\begin{array}{l}11 / 25 / 81 \\
06 / 28 / 82 \\
06 / 28 / 82\end{array}$ & $\begin{array}{l}1211 \\
1350 \\
0818\end{array}$ & $\begin{array}{l}207 \\
212 \\
213\end{array}$ & $\begin{array}{l}7.3 \\
6.9 \\
5.6\end{array}$ & $\begin{array}{l}-2 \\
-3 \\
-6\end{array}$ & $\begin{array}{l}10.4 \\
11.7 \\
10.4\end{array}$ & $\begin{array}{l}92 \\
60 \\
97\end{array}$ \\
\hline $\begin{array}{l}\mathrm{C} 2 \mathrm{a} \\
\mathrm{C} 2 \mathrm{~b} \\
\mathrm{C} 2 \mathrm{c}\end{array}$ & $\begin{array}{l}01 / 01 / 82 \\
12 / 04 / 81 \\
06 / 30 / 82\end{array}$ & $\begin{array}{l}1231 \\
1303 \\
1740\end{array}$ & $\begin{array}{l}196 \\
217 \\
188\end{array}$ & $\begin{array}{l}4.4 \\
5.2 \\
4.2\end{array}$ & $\begin{array}{r}-1 \\
-9 \\
9\end{array}$ & $\begin{array}{l}8.1 \\
7.1 \\
7.5\end{array}$ & $\begin{array}{l}177 \\
198 \\
195\end{array}$ \\
\hline $\begin{array}{l}\text { C3a } \\
\text { C3b } \\
\text { C3c }\end{array}$ & $\begin{array}{l}07 / 01 / 82 \\
12 / 18 / 81 \\
12 / 14 / 81\end{array}$ & $\begin{array}{l}0124 \\
1608 \\
1624\end{array}$ & $\begin{array}{l}199 \\
192 \\
208\end{array}$ & $\begin{array}{l}4.2 \\
2.2 \\
3.2\end{array}$ & $\begin{array}{r}0 \\
1 \\
-5\end{array}$ & $\begin{array}{l}13.4 \\
13.5 \\
14.0\end{array}$ & $\begin{array}{l}31 \\
36 \\
28\end{array}$ \\
\hline $\begin{array}{l}\text { C4a } \\
\text { C4b } \\
\text { C4c }\end{array}$ & $\begin{array}{l}01 / 01 / 82 \\
01 / 01 / 82 \\
01 / 01 / 82\end{array}$ & $\begin{array}{l}1803 \\
1546 \\
1825\end{array}$ & $\begin{array}{l}226 \\
199 \\
226\end{array}$ & $\begin{array}{l}3.5 \\
3.7 \\
3.5\end{array}$ & $\begin{array}{l}-6 \\
-7 \\
-6\end{array}$ & $\begin{array}{l}6.4 \\
6.5 \\
5.7\end{array}$ & $\begin{array}{l}199 \\
198 \\
199\end{array}$ \\
\hline
\end{tabular}

As we indicated in the previous chapter, the spikes in the rotationally sampled spectrum are caused by wind eddies that persist across the disk of rotation for multiple revolutions of the blade, while the floor represents smaller turbulent elements which appear to be random from one revolution to the next. The floor is thus dependent on the frequency content of the input wind spectrum at frequencies around the rotation rate, $0.667 \mathrm{~Hz}$. This in turn is a function of the input wind spectrum, the frequency response of the prope1ler anemometer, and any further filtering effects introduced during digital data processing. 
We presume there exists a lower limit of length scale for turbulent wind eddies, below which the wind turbine blade does not respond to the eddy. If this length scale is larger than the smallest eddy scale contained in the rotationally sampled wind spectrum, the flapwise bending moment spectrum will have a lower floor than the VPA wind spectrum. This is in fact what we observe for case Cla (Figures $6 \mathrm{a}$ and $\mathrm{C}$ ). We confirm this by computing the transfer function for this case (Figure 20b). An estimated blade response curve $H_{b}(n)$ is drawn as a curved dashed line. The computed transfer function $H(n)$ has a local dip at each of the floor regions: $0.5 P, 1.5 P, 2.5 P, 3.5 P$ and $4.5 P$.

The length scale $L$ of the input winds for the unfiltered VPA is about $3.3 \mathrm{~m}$, the distance constant of the propeller anemometer. This decreases the propeller spectral response to half the spectral density actually contained in the wind at a frequency

$$
n_{\frac{1}{2}}=\frac{\bar{u}}{2 \pi L}
$$

where $\bar{u}$ is the mean wind speed (Horst 1973). The smallest wind eddies can be filtered out using a running mean digital lowpass filter on the wind data at each location on the array before the data are rotationally sampled. This has the effect of adding an additional filter with a half power frequency of

$$
n_{\frac{1}{2}}=\frac{0.44}{S_{1} \Delta t}
$$

where $\Delta t$ is the digitization interval for the wind data (0.25 $\mathrm{s}$ in this case) and $S_{1}$ is the number of data points averaged together in the running mean (Powell and Connel1 1980). Figure 20c shows the spectrum of wind filtered in this way before being rotationally sampled, for $S_{1}=5$, giving a half-power frequency of $0.35 \mathrm{~Hz}$. In this spectrum the spikes are identical to those in the original VPA spectrum (Figure 20a), but the spectral density is reduced in the floor area. For a nine-point filter, with $n_{\frac{1}{2}}=0.20 \mathrm{~Hz}$, the drop in the floor area is about a factor of 10 below the original VPA spectrum (Figure 20e). 
These lowpass-filtered data were used to compute the transfer functions in Figures $20 \mathrm{~d}$ and $\mathrm{f}$. In Figure $20 \mathrm{~d}$, the use of five-point lowpass wind data results in all spectral minima being lifted up in the transfer function (solid line), giving a closer match to the expected transfer function. The largest discrepancy is in the $0.5 \mathrm{P}$ area. The nine-point lowpass gives a transfer function (Figure 20f) with spikes at $0.5 \mathrm{P}, 2.5 \mathrm{P}, 3.5 \mathrm{P}$ and $4.5 \mathrm{P}$. This indicates that the flapwise bending moment is responding at these frequencies to fluctuations not in the input wind spectrum.

Of the three transfer functions shown, we chose the five-point lowpass (Figure 20d) as showing the best correlation. This transfer function is flattest in the frequency range 0 to $0.3 \mathrm{~Hz}$, as desired, and is very close to the -2 rolloff 1 ine in the range 2 to $3.3 \mathrm{~Hz}(3 P-5 P)$. The blade response curve $H_{b}(n)$ plotted in Figures $20 \mathrm{~b}, d$ and $f$ has the parameters $n_{1}=1.5 \mathrm{~Hz}, n_{2}=4.3 \mathrm{~Hz}$, $Z_{1}=0.35$ and $Z_{2}=0.05$.

The harmonic frequencies $n_{1}$ and $n_{2}$ were taken from NASA testing. The damping coefficients $Z_{1}$ and $z_{2}$ were found by trial-and-error attempts to fit the observed transfer function in Figure $20 \mathrm{~d}$. The frequency range of VPA data was insufficient to predict the coefficient $Z_{2}$ at the frequency $4.3 \mathrm{~Hz}$, since the wind spectrum only extends to $4.0 \mathrm{~Hz}$, so the value of $z_{2}(0.05)$ is at best a very rough estimate.

The first flapwise harmonic damping coefficient, $z_{1}=0.35$, should be a useful estimate of the effective aerodynamic damping coefficient for the fiberglass MOD-OA blade. This best fit was obtained using wind data that were filtered effectively with a two-pole filter, which had a half-power frequency of $0.23 \mathrm{~Hz}$, or an effective distance constant of $5.2 \mathrm{~m}$. This indicates that the wind turbine sees only wind eddies with a size larger than about $5 \mathrm{~m}$.

\subsection{COMPARISON OF TRANSFER FUNCTIONS FOR VARIOUS CASES}

Wind characteristics of interest in evaluating the transfer functions in Figures 20, 21 and 22 are shown in Table 7. Generally, case C1 had the wind direction closest to the array direction of $205^{\circ}$ and relatively low yaw errors. This was due to the larger number of daytime below-rated cases, giving 

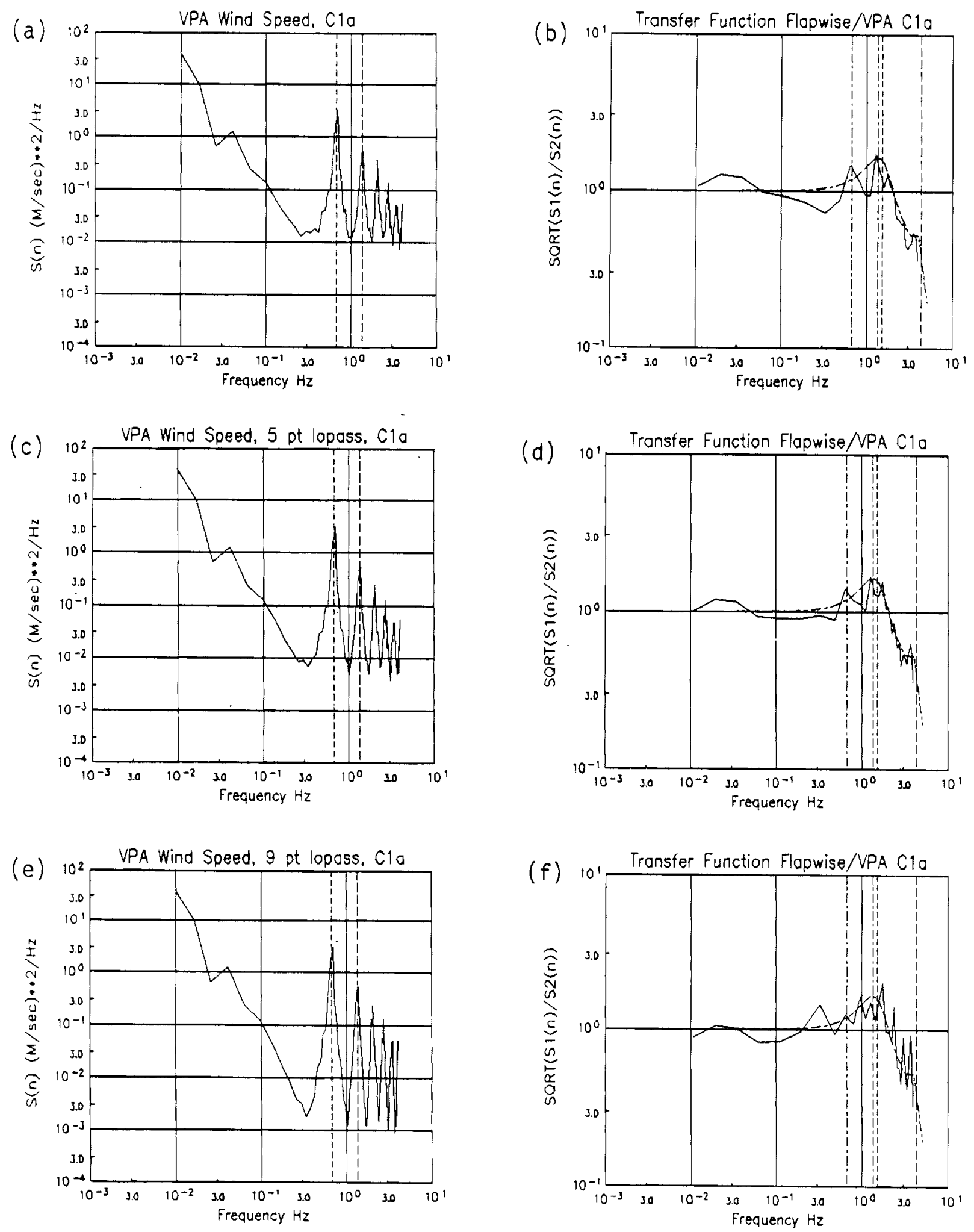
FIGURE 20. a) Spectrum of One-Blade Rotationally Sampled Wind, Case Cla; b) Corresponding Transfer Functions $H(n)$ (Solid Line) and $H b(n)$ (Dashed Line); c) Same as Part a, With Wind Data Filtered With a Five Point Lowpass Filter Before Rotational Sampling; d)

Transfer Functions Corresponding to Part c; e) Same as Part c, Nine Point Lowpass Filter; e) Transfer Function Corresponding to Part e. 

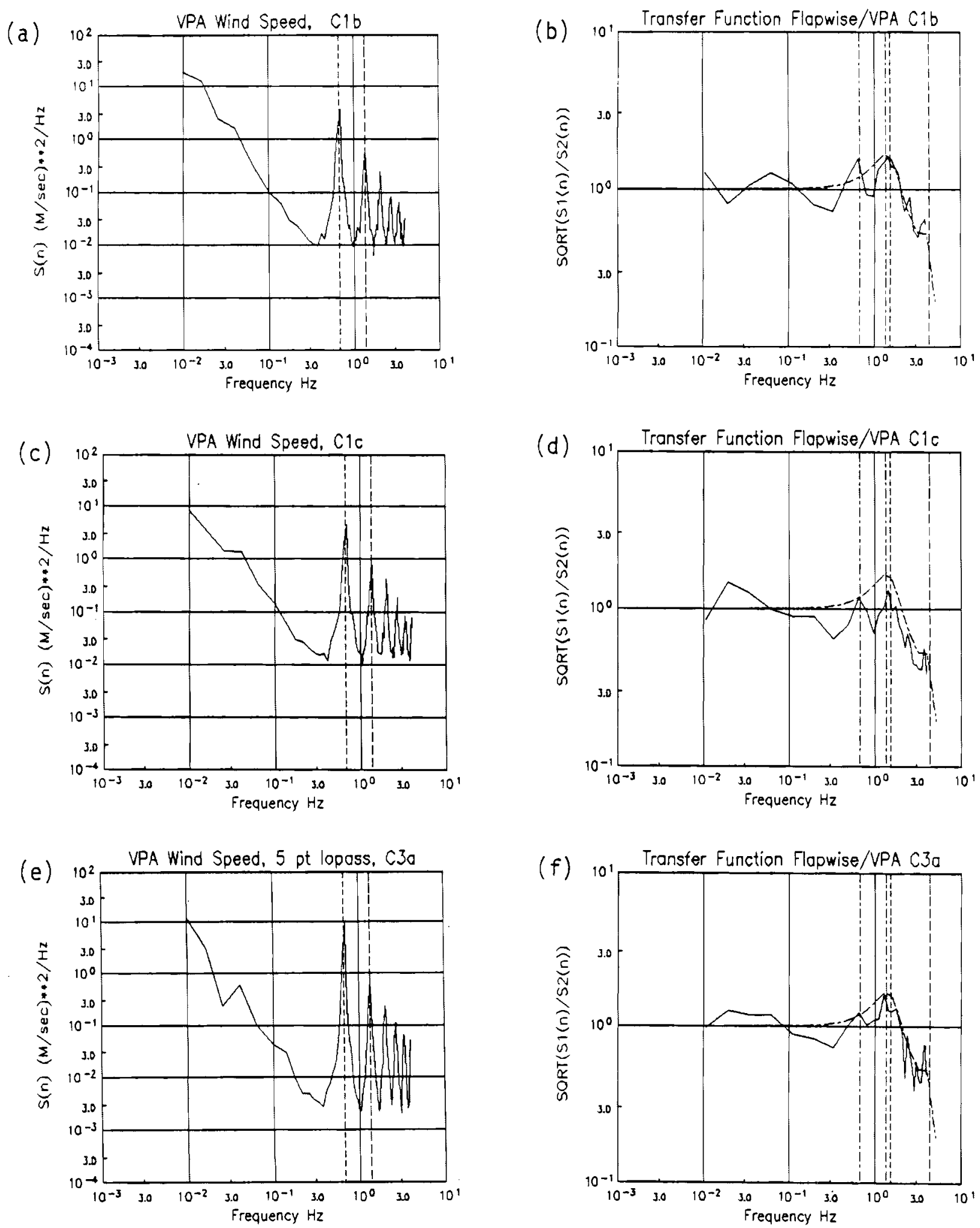

FIGURE 21. a) Spectrum of One-Blade Rotationally Sampled Wind, Clb; b) Transfer Functions for Part a; c) Same as Part a, Case C1c; d) Transfer Functions for Part c; e) Same as Part a, Five Point Lowpass, Case C3a; f) Transfer Functions for Part e. 

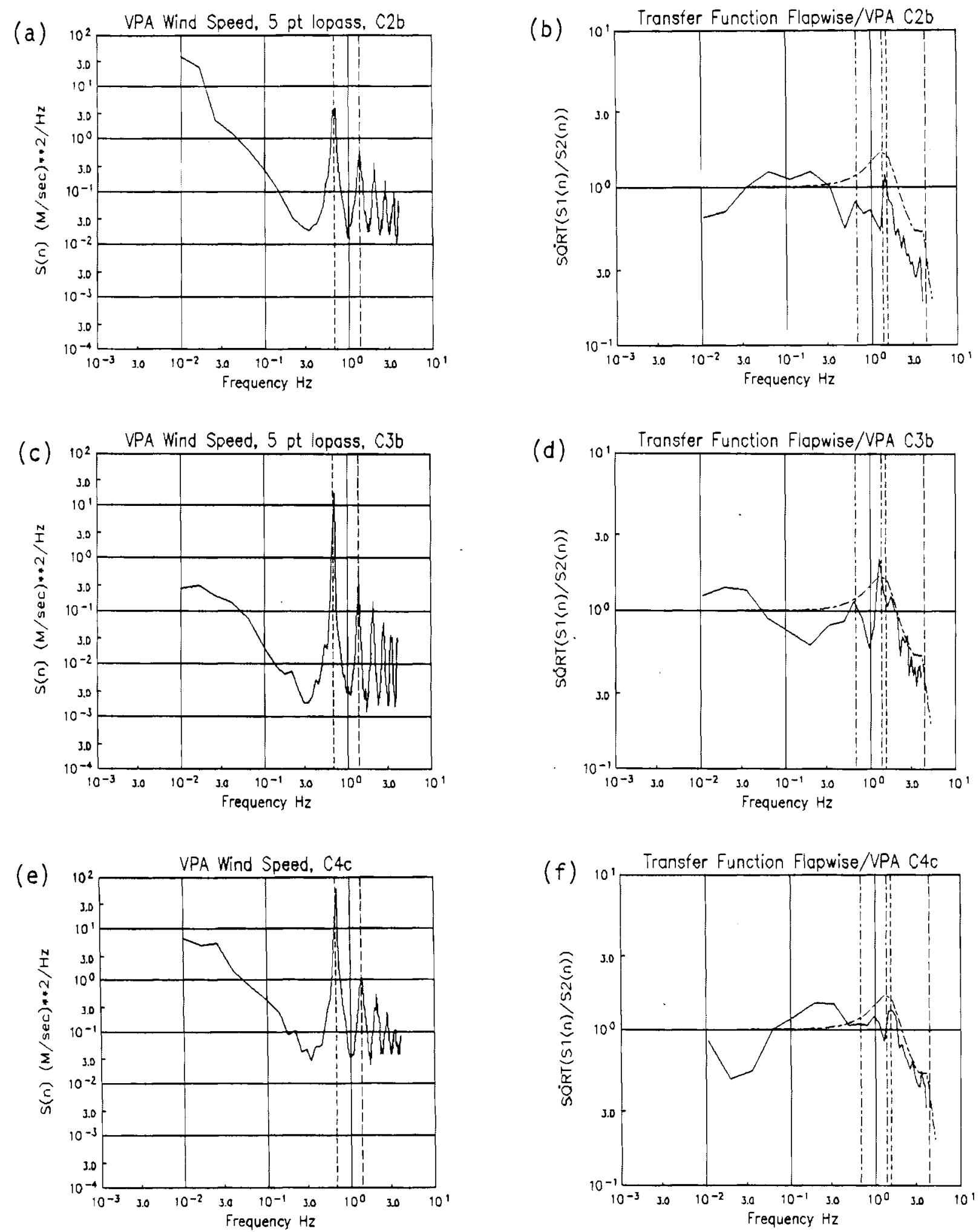

FIGURE 22. a). Spectrum of One-Blade Rotationally Sampled Winds, Five Point Lowpass, Case C2b; b) Transfer Functions for Part a; c) Same as Part a, Case C2b; d) Transfer Functions for Part c; e) Same as Part a, No Lowpass Filter, Case C4c; f) Transfer Functions for Part $f$. 
a better selection of data periods to analyze. Case C1 also had the largest variability in wind direction, as expressed by the standard deviation, $\sigma_{\theta}$. All data from cases $\mathrm{Cl}$ and $\mathrm{C} 3$ are below rated power. The higher wind speed cases in $\mathrm{C} 2$ have a worse selection of yaw errors and wind directions. The $\sigma_{\theta}$ is somewhat less, however. Case $\mathrm{C} 2 \mathrm{a}$ is partially above rated power of $200 \mathrm{~kW}$ and partially below, while the other five high-speed cases are essentially at rated power continuously.

The stable, low-wind-speed cases have relatively good wind directions and low yaw errors. The two highly stable cases, $C 3 b$ and $C 3 c$ have especially low $\sigma_{\theta}$. The high-wind, high-shear cases in C4 have a uniform yaw error of 6 to $7^{\circ}$ and a uniform $\sigma_{\theta}$ of 3.5 to 3.7. In cases $C 4 a$ and $C 4 c$, the wind direction was $21^{\circ}$ off the axis of the array, the farthest of any of the data cases.

After case Cla, three more cases had power below rated and turbulent winds, the most favorable conditions for a close match with the blade response. Transfer functions for each of these three cases (C1b, C1c and C3a) are shown in Figure 21. In both $\mathrm{C} 1 \mathrm{~b}$ and $\mathrm{ClC}$, the unfiltered VPA data were chosen over the five-point lowpass data because the latter gave higher spikes in the 2 to $3.3 \mathrm{~Hz}$ region. The same blade transfer function $H_{b}(n)$, experimentally derived for case Cla, is shown as a dashed line on the transfer function plots.

In C1b (Figure 21b), dips are apparent at 0.5P and 1.5P, and a spike is at $1 P$. The transfer function matches the blade response we 11 from $1.5 \mathrm{~Hz}$ to over $3 \mathrm{~Hz}$. This case had a yaw error of $3^{\circ}$ and wind direction $7^{\circ}$ off the array axis. In C1C (Figure 21d), the entire high-frequency portion was below the blade response curve. This was partially caused by a peak in response at very low frequencies $(0.02 \mathrm{~Hz})$. Since the transfer function curve was normalized using the average response from 0 to $0.33 \mathrm{~Hz}$, this peak in response serves to pull the entire transfer function curve down to lower values. A possible cause of the enhanced low-frequency response is long-duration excursions of the yaw error to high absolute values $\left(10^{\circ}\right.$ to $\left.15^{\circ}\right)$, which may alter the effect of the nacelle wake enough to affect blade response. Dips in the transfer function are also apparent at $0.5 \mathrm{P}$ and $1.5 \mathrm{P}$ for case $\mathrm{C} 1 \mathrm{C}$.

The slightly stable nighttime case, C3a (Figure 21f), had the best match using five-point lowpass filtered data. This looks almost the same as the 
first case Cla (Figure 20d), except for the extra spikiness at $4 \mathrm{P}$ and $5 \mathrm{P}$. This is probably due to a slight deviation in the rotation rate of the MOD-OA wind turbine from $40 \mathrm{rpm}$, due to poor frequency control of the diesel-powered Clayton city utility. Thus, the spikes do not quite coincide in frequency, leading to spikiness in the transfer function. This case had no mean yaw error. Thus, the two turbulent low-wind cases with the lowest yaw error look very similar (Cla and $\mathrm{C} 3 \mathrm{a}$ ).

Examples of above-rated and low-turbulence cases are shown in Figure 22 . For the neutral above-rated case C2b (Figure 22b) the pitch control decreases the blade response at low frequencies while enhancing the response at around 0.05 to $0.3 \mathrm{~Hz}$. The higher frequency part of the transfer function is much reduced. This case had the largest mean yaw error and large excursions in yaw error. The five-point lowpass filtered wind data provided the smoothest rolloff line. In case C3b, a highly stable, low-wind-speed case, deep dips exist at $0.5 \mathrm{P}, 1.5 \mathrm{P}$, etc. even using the five-point lowpass filtered winds. The strong response at $2 P$ suggests the possibility that aerodynamic damping may be less in low-turbulence winds.

The last case presented, C4C (Figure 22f) was a case with high wind speed, high shear, and very stationary wind speed and direction. The pitch control system served to lessen the blade stress in the low-frequency part of the spectrum and increase it around $0.2 \mathrm{~Hz}$. The high-frequency part of the transfer function was also reduced somewhat compared to the low-frequency part. Thus, al1 three cases that showed this phenomenon ( $C 1 c, c 2 b, c 4 c$ ) had large mean and/or fluctuating yaw errors.

\subsection{EVALUATION OF TRANSFER FUNCTION TECHNIQUE}

The transfer function approach was undertaken for two reasons. The first was to verify that the rotationally sampled wind using VPA data is a valid predictor of wind turbine blade response, and to gain experience and knowledge of the scales of motion in the wind that produce stresses in the wind turbine. The second objective was to demonstrate a technique for deriving the amount of damping of flapwise oscillations that a wind turbine blade undergoes while operating in the atmosphere, using wind measurements correlated with wind turbine measurements. 
To verify that the VPA wind data are a valid predictor of blade response, we first confirm by visual inspection of VPA and blade flapwise spectra, that a) the spectra look alike, and b) the flapwise bending moment spectrum has enhanced response at $1.5 \mathrm{~Hz}$ and $4.3 \mathrm{~Hz}$, as expected from blade testing. After computing our best-fit transfer functions, we observe that the rolloff from the first harmonic peak has a -2 slope for all cases, and has the right magnitude for all cases with low yaw error. For low frequencies, the transfer function is close to 1.0 for all cases with low yaw error and below-rated winds.

The use of digital lowpass filtering to match the length scale of the wind model and the wind turbine response met with limited success. The transfer functions for some cases were much better behaved than in other cases, perhaps due to variations in wind turbine rotor frequency. A substantial decrease in blade response in the floor regions for lower harmonics is evident in most cases, especially at 1.5P. The cause of this is unknown.

The key unknown parameter, which we estimated using the transfer function approach, is the damping coefficient of the first flapwise harmonic of the blade, which we estimate to be 0.35 for turbulent winds in below-rated cases. All three of our transfer functions for cases with low yaw error in turbulent winds and below-rated power ( $\mathrm{Cla}, \mathrm{Clb}, \mathrm{C} 3 \mathrm{a}$ ), matched this damping coefficient in the region from $2 \mathrm{P}$ to $5 \mathrm{P}$. One case ( $\mathrm{C} 3 \mathrm{~b}$ ) suggests that the damping coefficient may be lower for less turbulent winds. 


\subsection{ESTIMATION OF HARMONIC VARIANCES FROM SINGLE TOWER DATA}

We have shown that the spectrum of VPA rotationally sampled winds correlates highly with the spectrum of blade bending moment of the MOD-OA. The wind spectra we have seen have a very similar form for various wind speeds and stabilities. In particular, the spectra of rotationally sampled winds, with the mean shear removed, which we have attributed to turbulence in the wind, are very regular and well-behaved.

The variances in the wind speed associated with each harmonic of the rotation frequency $n_{0}$ have been shown to be a useful means of simplifying the spectral data. A tabulation of the variances for the first five harmonics, such as in Tables 4 and 5, contains the most basic feature of the spectra. These can be used to estimate the total response of the wind turbine once a physical relationship between the word and turbine response, such as the blade transfer function presented in Chapter 4 , has been established. Thus, if we can estimate the variance in each harmonic "spike" for any given wind situation, we can address issues such as loads testing and long-term estimation of the fatigue cycles affecting the blade.

From the Clayton data set, it is possible to look at a statistically large set of VPA and MOD-OA data directly, using spectra computed from the rotationally sampled time series. However, this might not be a practical approach, if we wish to develop a technique that is generally useful to wind turbine designers. Therefore, we wish to estimate the harmonic variances from a much more limited data set.

As an initial attempt at estimating the harmonic variances, we take the neutral-to-unstable cases $\mathrm{C} 1$ and $\mathrm{C} 2$. In Chapter 3 , we demonstrated that the variance due to turbulence at all harmonics, and the relative variance in each harmonic, obeyed simple linear relationships. We will use these relationships to estimate the variance at each harmonic, given a limited amount of data.

We choose case $\mathrm{Clc}$ at random to use as an example. We are given 1) neutral-to-unstable turbulent winds, 2) wind speed $w_{s}=7.68 \mathrm{~ms}^{-1}$, and 3) total shear across the disk $=0.955 \mathrm{~ms}^{-1}$. These are data available from a single tower. We assume 
1. $\sum_{i=1}^{5} \sigma_{i t}{ }^{2}=0.072+0.040 w_{s}=0.379 \mathrm{~m}^{2} \mathrm{~s}^{-2}$

is the variance for all five spikes, mean shear removed

2. $\sigma_{1 \mathrm{~s}}{ }^{2}=\left(\frac{\sqrt{2}}{4} \times \text { total shear }\right)^{2}=0.114$

is the variance due to mean shear. We assume the shear is linear, and assign all this variable to the $1 \mathrm{P}$ spike.

3. $\sigma_{i t}{ }^{2}=k_{0}\left(i n_{0}\right)^{k_{1}}$, choosing $k_{1}=-1.45$

as being a representative slope for neutral-unstable, low wind speed. We then solve to find $k_{0}$

$$
\begin{aligned}
k_{0} & =\frac{\sum_{i=1}^{5} \sigma_{i t}{ }^{2}}{\sum_{i=1}^{5}\left(i n_{0}\right)^{k_{1}}}=\frac{0.379}{1.8+0.69+0.37+0.24+0.17}=0.117 \\
\sigma_{1}^{2} & =(0.117)\left(n_{0}\right)^{-1.45}+0.114=0.324 \\
\sigma_{2}^{2} & =(0.117)\left(2 n_{0}\right)^{-1.45}=0.081 \\
\sigma_{3}^{2} & =0.043 \\
\sigma_{4}^{2} & =0.028 \\
\sigma_{5}^{2} & =0.020 .
\end{aligned}
$$

These are our model estimates of the variance in each harmonic of the VPA one-blade rotationally sampled spectrum. For comparison, the actual values were (Table 4) 


$$
\begin{aligned}
& \sigma_{1}^{2}=0.310 \\
& \sigma_{2}^{2}=0.102 \\
& \sigma_{3}^{2}=0.055 \\
& \sigma_{4}^{2}=0.033 \\
& \sigma_{5}{ }^{2}=0.025 .
\end{aligned}
$$

Thus, the model predicts the observed values with an error of $+5 \%$ for the $1 P$ spike and about $-20 \%$ for the higher spikes. The total variance, mean shear plus turbulence, is $0.114+0.379=0.493 \mathrm{~m}^{2} \mathrm{~s}^{-2}, 6 \%$ in error.

This model could be improved in many ways, depending on the accuracy desired and the type of data used as input. Included among these improvements might be the use of turbulence statistics from the single tower as well as means. Since the rotationally sampled spectrum is actually a manifestation of instantaneous wind shears across the disk of rotation, a model incorporating statistics of fluctuating shears should be even more accurate.

We again caution the reader that this model applies only to the MOD-OA configuration over flat terrain. For complex terrain, site-specific turbulent wind measurements with one or more towers instrumented at many levels are recommended. For other wind turbines, especially of different sizes, a program of field testing in conjunction with close upwind measurement of the wind from towers, or wind measurements directly from the rotor, will be required.

Ultimately, the form of the model and the degree of accuracy required must be determined by the wind turbine design application. Therefore, the maximum amount of communication and joint planning between wind model developers and wind turbine designers must take place. 
. 


\subsection{CONCLUSIONS AND RECOMMENDATIONS}

In this study, the free-stream turbulent wind has been measured using an array of fixed anemometers located two blade diameters upwind of an operating horizontal-axis wind turbine (HAWT). The wind as seen by the rotating HAWT blade has been closely approximated using the anemometer data, rotationally sampled at the same rotational speed as the MOD-OA wind turbine. Twelve data cases have been analyzed, divided into four wind regime classes: $\mathrm{C} 1$, neutralto-unstable daytime conditions, lower wind speeds, wind turbine operating below rated power; $\mathrm{C2}$, neutral-to-unstable daytime conditions, higher wind speeds, wind turbine at rated power; $\mathrm{C3}$, stable nighttime conditions, low wind speeds, low turbulence; C4, stable evening cases; high wind speeds, high turbulence. Observed spectra of rotationally sampled wind have been compared with observed MOD-OA wind turbine parameters.

For several data cases, the rotationally sampled wind was compared with the MOD-OA blade bending moment by computing a transfer function between the input winds and blade bending response. This was compared to the expected blade bending response based on static tests of blade resonance. A method of estimating the aerodynamic damping of the blade using these transfer functions was demonstrated.

In the following sections, conclusions drawn from this study are presented for rotationally sampled winds and for wind turbine response transfer function correlations. In a final section, a method of estimating the variance in the rotationally sampled wind spectrum using a limited amount of data, such as might be obtained from a single meteorological tower, is presented.

\subsection{CONCLUSIONS RELATING TO SPECTRAL ANALYSIS OF ROTATIONALLY SAMPLED WIND DATA}

- Generally, the characteristic rotationally sampled spectrum, with spikes at all harmonics of the blade rotation rate for one-blade wind speed and at even harmonics only for two-blade winds, occurs for all wind regimes. In all cases, parts of the high frequency spectrum exceed the theoretical 
fixed-point Eulerian spectrum. At higher wind speeds (1ower tip speed ratios), the spikes are broader and the floor between the spikes is higher.

- The one-blade rotational spectrum, sampled after removing the mean wind speed from each point on the array, has the same five-spike characteristic as the original spectrum. Thus, the five-spike spectrum is a manifestation of turbulent, stochastic winds.

- The wind speed variances associated with each of the first five harmonics of the blade rotation frequency $n_{0}$ follow some very predictable patterns. For all cases in this flat terrain, the variance decreases monotonically with increasing frequency. The total variance can be summed from the turbulent variance and the variance due to mean wind shear. The latter variance is concentrated almost entirely in the first rotational harmonic (1P). The variance due to turbulence is $80 \%$ of the total variance in wind regime $\mathrm{C} 1,65 \%$ in $\mathrm{C} 2,30 \%$ in $\mathrm{C} 4$ (high shear, high turbulence) and less than $15 \%$ in $C 3$ (for high shear, very low turbulence cases). In a11 cases, the variance at the higher harmonics of the rotor frequency ( $3 \mathrm{P}$ and above) is almost completely due to turbulence in the wind.

- The sum of the variance at all harmonics due to turbulence is a linearly increasing function of wind speed for cases $\mathrm{C} 1$ and $\mathrm{C} 2$ (neutral-unstable cases). The increase is about $0.04 \mathrm{~m}^{2} \mathrm{~s}^{-2}$ variance for each $1 \mathrm{~ms}^{-1}$ increase in wind speed. The $C 3$ data (low turbulence) fall below this line, while the C4 data show greater turbulent variance versus wind speed, as well as much greater variance associated with mean wind shear.

- The amount of variance contained in each harmonic spike decreases with increasing frequency by a power law, giving a straight line on a log-log plot of harmonic variance versus frequency. The slope of this line ranges from -1.5 to -1.25 for neutral-to-unstable cases, with some tendency for the steeper slope $(-1.5)$ to be associated with lower wind speeds (higher tip speed ratios). 
6.2 CONCLUSIONS RELATING TO THE CORRELATION BETWEEN ROTATIONALLY SAMPLED WINDS AND MOD-OA WIND TURB INE RESPONSE

- The spectra of flapwise bending moments are very well correlated with the one-blade VPA rotationally sampled wind spectra. For below-rated cases, $\mathrm{Cl}$ and $\mathrm{C} 3$, the qualitative correlation is high for all frequencies. Above rated power, in cases $\mathrm{C} 2$ and $\mathrm{C} 4$, the correlation is less for low frequencies $(<0.5 \mathrm{~Hz})$, due to pitch control of power and (indirectly) blade stress.

- The spectra of MOD-OA generator power are less well correlated with the two-blade VPA wind spectra. The generator power spectra contain effects at higher frequencies that do not seem related to the input wind, as we11 as pitch control effects at lower frequencies in above rated cases.

- Both flapwise and power spectra show enhanced response at the resonant frequencies of flapwise motion for the fiberglass MOD-OA blade, $1.5 \mathrm{~Hz}$ and $4.3 \mathrm{~Hz}$ (first and second flapwise harmonics).

- Transfer functions were computed using the VPA one-blade wind spectrum as the input and the flapwise bending moment as the response. These show a realistic correlation with the expected blade bending response frequencies. The most consistent feature of the computed transfer functions is a rolloff with a slope of -2 occurring at frequencies higher than the first flapwise harmonic of $1.5 \mathrm{~Hz}$.

- Using the computed transfer functions, we estimate the damping coefficient of the first flapwise resonance to be 0.35 . This result is consistent for the three best data cases below rated power. Above rated power, pitch control makes the computed transfer functions less consistent. The second blade harmonic, $4.3 \mathrm{~Hz}$, has a much lower damping coefficient, but a reliable estimate could not be made because of data limitations.

- The quality of the transfer functions was lower for cases with yaw errors greater than $5^{\circ}$, with a tendency for greater blade bending response at low frequencies $(<0.1 \mathrm{~Hz})$ in these cases. This may be due to effects of the nacelle wake on the downwind rotor. 


\subsection{REFERENCES}

Chan, S. M., D. C. Powe11, M. Yoshimura and D. H. Curtice. 1983. "Operations Requirements of Utilities With Wind Power Generation." IEEE Transactions on Power Apparatus and Systems, PAS-102(9):2850-2860.

Conne11, J. R. 1981. The Spectrum of Wind Speed Fluctuations Seen by a Rotating Blade of a Wind Energy Conversion System: Observations and Theory. PNL-4083, Pacific Northwest Laboratory, Richland, Washington.

Connel1, J. R. and R. L. George. 1982. The Wake of the MOD-OAl Wind Turbine at Two Rotor Diameters Downwind on December 3, 1981. PNL-4210, Pacific Northwest Laboratory, Richland, Washington.

Conne11, J. R. and R. L. George. 1983. "A New Look at Turbulence Experienced by a Rotating Wind Turbine." Presented at the Energy Sources Technology Conference and Exhibition, January 30 - February 3, 1983, Houston, Texas. American Society of Mechanical Engineers, New York.

Conne11, J. R., R. L. George, and V. R. Sandborn. 1984. Rotationally Sampled Wind and Wind Turbine Response at Goodnoe Hills MOD-2, Unit No. 2, Measured in JuTy-August, 1983: A Preliminary Analysis. Electric Power Research Institute, Palo Alto, California.

Doran, J. C. and K. R. Packard. 1982. Comparison of Model and Observations of the Wake of a MOD-OA Wind Turbine. PNL-4433, Pacific Northwest Laboratory, Richland, Washington.

George, R. L. 1984. Simulation of Winds as Seen by a Rotating Vertical-Axis Wind Blade. PNL-4914, Pacific Northwest Laboratory, Richland, Washington.

Horst, T. W. 1971. "A Computer Algorithm for Correcting Noncosine Response in the Gill Anemometer," in Pacific Northwest Laboratory Annual Report for 1971 to the USAEC Division of Biology and Medicine, Vol. II: Physical Sciences, Part I: Atmospheric Sciences. BNWL-1651-1, Pacific Northwest Laboratory, Richland, Washington.

Horst, T. W. 1973. "Corrections for Response Errors in a Three-Component Propeller Anemometer." J. of App1. Meteor., 12(6):716-725.

Miller, A. H. and W. J. Formica. 1984. Development and Verification of MOD-2 and MOD-OA Simulation Models. PNL-4864, Pacific Northwest Laboratory, Richland, Washington.

Neustadter, H. E. 1979. "The Use of Wind Data With an Operational Wind Turbine in a Research and Development Environment." In Proceedings of Conference and Workshop on Wind Energy Characteristics and Wind Energy Siting 1979. American Meteorological Society, Boston, Massachusetts. 
Powe11, D. C. and J. R. Connel1. 1980. Definition of Gust Model Concepts and Review of Gust Models. PNL-3138, Pacific Northwest Laboratory, Richland, Washington.

Sandborn, V. A. and J. R. Conne11. 1984. Measurement of Turbulent Wind Velocities Using a Rotating Boom Apparatus. PNL-4888, Pacific Northwest Laboratory, Richland, Washington.

Spera, D. A. 1977. Comparison of Computer Codes for Calculating Dynamic Loads in Wind Turbines. NASA TM-73773, NASA Lewis Research Center, Cleveland, Ohio.

Sullivan, T. L. 1983. Structural Qualification Testing and Operational Loading on a Fiberglass Rotor Blade for the MOD-0A Wind Turbine. NASA TM-83309, NASA-Lewis Research Center, Cleveland, Ohio.

Verholek, G. 1978. Preliminary Results of a Field Experiment to Characterize Wind Flow Through a Vertical Plane. PNL-2518, Pacific Northwest Laboratory, Richland, Washington.

Weingart, 0 . 1982. Low-Cost Composite Blades for the MOD-OA Wind Turbines. pp. 239-258, NASA Conference Publication 2230, D0E Publication CONF-810752, National Technical Information Service, Springfield, Virginia. 


\section{DISTRIBUTION}

No. of

Copies

OFFSITE

D. Ancona

Department of Energy

Wind Energy Technology Division

1000 Independence Avenue

Forrestal Building, Room $5 \mathrm{HO} 48$

Washington, DC 20585

J. Cadogan

Department of Energy

Wind Energy Technology Division

1000 Independence Avenue

Forrestal Building, Room $5 \mathrm{HO} 48$

Washington, DC 20585

G. P. Tennyson

Department of Energy

Albuquerque Operations Office

P. 0. Box 5400

A7buquerque, NM 87110

27 DOE Technical Information Center

Peter Lissaman

Aerovironment, Inc.

145 Vista Avenue

Pasadena, CA 91107

Tom Gray

American Wind Energy Association 2010 Massachusetts Avenue

Fourth Floor

Washington, DC 20036

C. I. Aspliden

Battelle Memorial Institute

2030 M Street N.W.

Washington, DC 20036

Don McGrew

Boeing Engineering and Construction

P.0. Box 3707, Mail Stop 9A-67

Seattle, WA 98124
No. of

Copies
2 Dr. Edgar DeMeo/Frank Goodman, Jr. Electric Power Research Institute 3412 Hillview Avenue

Palo Alto, CA 94303

George Ficht 1

7703 Oakridge Drive

Huntsville, AL 35802

2 Tom Hiester/J. J. Riley

Flow Wind Corporation

21414-68th Avenue South

Kent, WA 98031

2 J. M. Kos/Eugene Di Valentin

Hamil ton Standard

Bradley Field Road

Windsor Locks, CT 06096

M. A. Bowes

Kaman Aerospace Corporation

0ld Windsor Road

Bloomfield, CT 06095

David Spera

NASA/Lewis Research Center

21000 Brookpark Road

Cleveland, $\mathrm{OH} 44135$

Joe Savino

Wind Turbine Group

NASA/Lewis Research Center

21000 Brookpark Road

Cleveland, $\mathrm{OH} \quad 44135$

Phillip French

NASA Scientific and Technical Information Facility

P.0. Box 8757

Baltimore/Washington International Airport

Baltimore, MD 21240 
No. of

Copies

Jerry Gregorck

Ohio State University

Columbus, $\mathrm{OH} 43210$

Peter M. Moretti

Oklahoma State University

Mechanical and Aerospace

Engineering

Engineering North 218

Stillwater, OK 74074

R. Lee Cresap

Pacific Gas \& Electric Company Room 1385

77 Beale Street

San Francisco, CA 94106

2 J. Dutton/H. A. Panofsky

Department of Meteorology

Pennsylvania State University

University Park, PA 16902

J. P. Sullivan

331 Grissom Hall

Purdue University

West Lafayette, IN 47907

Jim Tangler

Rockwell International

Rocky Flats Plant

P.0. Box 464

Golden, CO 80401

E. Kadlec

Sandia Laboratories

Division 5443, P. 0. Box 5800

Albuquerque, NM 87115

Paul Veers

Sandia Laboratories

Division 1524, P.0. Box 5800

Albuquerque, NM 87115

Robert Noun

Solar Energy Research Institute

1617 Cole Boulevard

Golden, C0 80401
No. of

Copies

R. W. Thresher

Oregon State University

Corvallis, OR 97331

Sherman M. Chan

Systems Control, Inc.

1801 Page Mil1 Road

P.0. Box 10025

Palo Alto, CA 94303

J. H. Strickland

Mechanical Engineering Department

Texas Tech University

Lubbock, TX 79409

R. H. Kirchhoff

Department of Mechanical

Engineering

University of Massachusetts

Amherst, MA 01003

Earl L. Davis

U.S. Windpower, Inc.

2305 S. Vasco Road

Livermore, CA 94550

W. A. Vachon

P.0. Box 149

Manchester, MA 01944

Paul Vosburgh

VAWT Power, Inc.

Albuquerque, New Mexico

H. Tielman

Department of Engineering Science \& Mechanics

Virginia Polytechnic Institute and State University

Blacksburgs, VA 24061

R. E. Akins

Associate Professor of Engineering Washington and Lee University

Lexington, VA 24450 
No. of

Copies

Farrell Smith Seiler Wind Energy Report

Box 14 - 104 S. Village Avenue Rockville Centre, NY 11571

Dr. V. Barros

28 De Julio 28

9120 Puerto Madryn

Chulret R. ARGENTINA

Lawrence Schienbein

DAF Indal

Mississauga, Ontario

CANADA

Bernard Masse

1800 Montee Ste-Julie

Varennes

Quebec, CANADA JOL 2PO

R. J. Templin

National Research Council of Canada

National Aeronautical

Establishment

M-2 Montreal Road

Ottawa, Ontario

CANADA K1A OR6

Leif Kristensen

Department of Physics

Ris $\emptyset$ Nationa 1 Laboratory

4000 Roskilde

DENMARK

Per Lundsager

Ris $\varnothing$ Nationa 1 Laboratory

P.0. Box 49

DK-4000 Roskilde

DENMARK

Professor Sir Martin Ryle

Cavendish Laboratory

Madingley Road

Cambridge CB3 OHE

ENGLAND
No. of

Copies

H. H. Rosenbrock

The University of Manchester

Institute of Science and

Technology

P.0. Box No. 88

Manchester M60 1QD

ENGLAND

D. Lindley

Taylor Woodrow Construction, Ltd.

Taywood House

345 Ruislip Road

Southa 11

Middlesex UBI 2QX

ENGLAND

Andre Laneville

University of Sherbrooke

Quebec, CANADA

Dr. Werner Dub

Forschungsprojekt Windenergie

Universitatsstrasse 31

D-8400 Regensburg

GERMANY, FRG

Dr. Neil Cherry

Lincoln College

Canterbury

NEW ZEALAND

Dr. 011 e Ljungstrom

FFA, The Aeronautical Research Institute

Forskningsstationen i Stockholm

Drottning Kristinas Vag 47

S-114 29 Stockholm

SWEDEN

ONSITE

DOE Richland Operations Office

H. E. Ransom 
No. of

Copies

40 Pacific Northwest Laboratory

J. R. Connell

D. W. Dragnich

D. L. Elliott

R. L. George (5)

P. C. Hays

S. K. Heflick

T. E. Michener

A. H. Miller
No. of

Copies

V. R. Morris

E. L. Owczarski

D. C. Powell

D. S. Renne

H. L. Wegley

L. L. Wende 11

Technical Information Files (5)

Publishing Coordination (2)

WCPE Program Office (15) 